\title{
DESEMBOLSOS DO BNDES AO SETOR SUCROENERGÉTICO E OS PROCESSOS DE HOMOGENEIZAÇÃO TERRITORIAL ENERGÉTICO NO ESTADO DE SÃO PAULO
}

\author{
Ana Claudia Giannini Borges \\ Departamento de Economia, Administração e Educação/Campus de Jaboticabal e Pós-Graduação em \\ Geografia/Campus de Rio Claro - Universidade Estadual Paulista - UNESP \\ ana.giannini@unesp.br \\ José Gilberto de Souza \\ Departamento de Geografia e Pós-Graduação em Geografia/Campus de Rio Claro \\ Universidade Estadual Paulista - UNESP \\ jgilbert@rc.unesp.br
}

\begin{abstract}
RESUMO
A relação mercado e Estado no setor sucroenergético se modifica diante da inserção e padrão de importância que assume na economia doméstica e mundial, em períodos de maior ou menor intervenção estatal. Uma articulação (Estado-mercado) que vai delineando as formas de expansão e retração espacial, bem como estruturando padrões de concentração da propriedade e uso da terra, sobretudo no estado de São Paulo. Mesmo frente ao processo de desregulamentação imposto ao setor, observa-se que, dada sua posição na economia doméstica, na produção de commodities e atuação bursátil, o Estado, via BNDES, ainda disponibiliza recursos e viabiliza suas estratégias de expansão espacial e articulação financeira. Frente ao exposto, o artigo analisa os desembolsos do BNDES no estado de São Paulo, por finalidade e por município, microrregião e mesorregião, no período de 2000 a 2012, bem como seu impacto na produção e na diversidade produtiva. Verificou-se que tais processos resultam em um padrão de homogeneização territorial, compreendido como determinação das lógicas de consolidação hegemônica do agronegócio, ao aprofundar as relações mercantis e financeiras na agricultura nacional.
\end{abstract}

Palavras-chave: Expansão sucroenergética. Antivalor. Financeirização da natureza. Estado. Fundos públicos.

\section{BNDES DISBURSEMENTS TO THE SUGAR AND ALCOHOL SECTOR AND THE ENERGY TERRITORIAL HOMOGENEIZATION PROCESSES IN THE STATE OF SÃO PAULO}

\begin{abstract}
The relationship between the market and the state in the sugar and alcohol sector changes during the insertion and importance in the context of the development / economic growth of Brazil and it relationship with the world economy, with periods of greater or lesser state intervention. This articulation (Market State) determines the forms of spatial expansion and retraction, as well as structure patterns of concentration of land ownership and use, especially in the State of São Paulo. Even in the face of deregulation, it can be observed that, given the sector's position in the production of commodities, clean energy and operator in future markets, the State, through the National Economic Development Bank (BNDES), still provides resources and enables its strategies of spatial expansion and financial articulation. In view of the above, the objective of this study is to analyze BNDES disbursements in the state of São Paulo, by purpose, by municipality, microregion and mesoregion, from 2000 to 2012, as well as their impacts on production and productive diversity. It is considered that these processes result in a territorial homogenization standard, understood as determination of the hegemonic consolidation logic of the agribusiness, by deepening the dependent, mercantile and financial relations of Brazilian agriculture.
\end{abstract}

Key Words: Sugarcane expansion. Anti-value. Financialization of nature. State. Public funds. 


\section{INTRODUÇÃO}

Estado e mercado sempre apresentaram relações efetivamente imbricadas, considerando o papel que o primeiro apresenta na consolidação da forma valor. Esse processo acentua-se com o advento do neoliberalismo. No Brasil, um exemplo particular, se circunscreve ao setor sucroenergético que modifica sua relação diante de sua inserção e padrão de importância no contexto da economia nacional e mundial, que se inicia desde sua implementação nos anos 1970, mais especificamente com o Proálcool, passando pelo processo de desregulamentação do setor com a extinção do Instituto do Açúcar e do Álcool, nos anos 1990. As imbricações frente à lógica de financeirização da economia são aprofundas a partir dos anos 2000, com as trajetórias de diversificação produtiva (açúcar, etanol e energia), as fusões e aquisições e a internacionalização e ou desnacionalização do setor. (BACCARIN, 2019; BORGES e BRUMATTI, 2019). Diante do exposto, o presente artigo objetiva analisar como esta imbricada relação apresenta desdobramentos socioespaciais e territoriais, considerando a atuação de um de seus aparelhos de políticas de desenvolvimento e crescimento econômico mais eficazes no período de 2003 a 2012, o Banco Nacional de Desenvolvimento Econômico e Social (BNDES). Tais desdobramentos dão a conformação clara de um movimento de apropriação corporativa do espaço, de um ajuste espacial (HARVEY, 2005), e a consolidação territorial, como expressão concreta das relações de poder (RAFFESTIN, 1993), que se materializam como determinações territoriais. Do ponto de vista empírico, a análise se estrutura sobre o volume de créditos liberados no estado de São Paulo para o setor sucroenergético, viabilizando suas estratégias de expansão espacial e articulação financeira, visto que, segundo Baccarin (2019) e Borges e Brumatti (2019) este estado é o principal produtor do setor.

Considera-se que tais créditos ampliaram a estrutura produtiva, o volume de capitais das empresas e, simultaneamente, produziram uma inserção no mercado internacional de commodities, por sua vez, dependente, subordinada e com tendência a deterioração dos termos de troca. O Presidente Luis Inácio Lula da Silva, em seu discurso na abertura do Debate-Geral da 62a Assembleia-Geral das Nações Unidas de 2007, destaca que há a necessidade de o mundo buscar uma nova matriz energética, em que o "etanol e o biodiesel podem abrir excelentes oportunidades" a vários países (BRASIL, 2007). Reafirmando este posicionamento, observou-se no Brasil uma política externa que primava pela formação do mercado internacional de etanol, a fim de estimular a sua "commoditização" (KLOSS, 2012). Conjuntamente, o governo favorece a consolidação de grandes empresas brasileiras como players mundiais, inclusive com financiamento do BNDES (BUGIATO, 2014). É importante destacar que a estrutura de capital do BNDES é constituída, principalmente, por fontes governamentais, sendo de $84,3 \%$ no ano de $2016,83,5 \%$ em $2017,78,8 \%$ em 2018 e $74,4 \%$ em 2019 (BNDES, 2020).

O BNDES, nesse contexto, promoveu a inserção de um significativo montante de recursos ao setor sucroenergético, com intenção de garantir a produção e suprir o crescente consumo de etanol, vis-àvis a demanda de investimentos no parque fabril (agrícola e industrial). (MILANEZ; BARROS; FAVERET FILHO, 2008). Dessa forma, o setor sucroenergético e outros setores agroindustriais foram favorecidos por um arranjo econômico-político realizado pelo Estado no período em análise, com o intuito de superar a crise de liquidez externa (dos anos de 1998 até 2002), retomando e ou reforçando a dependência dos setores primários de exportação, para composição de superávits no balanço de pagamentos. Esse processo, segundo Delgado (2010, p. 111), concorre à “[...] expansão das cadeias agroindustriais, do sistema de crédito público e do mercado de terras, coetânea à expansão dos mercados mundiais de "commodities'", em uma lógica que assenta nova dinâmica na agricultura brasileira e coaduna nos grandes grupos econômicos, com a detenção de propriedade da terra e capital agrícola e industrial (OLIVEIRA, 2016). Juntamente se amplia a incorporação de terras "às atividades hegemônicas", dando "um padrão homogêneo de seu uso, concorrendo com alterações nos preços, no mercado e nas relações de propriedade e de posse." (SOUZA, 2013, p. 30)

Os volumes de desembolsos do BNDES no estado de São Paulo são apresentados por finalidade ${ }^{1} \mathrm{e}$ por município, microrregião e mesorregião, na primeira década do século XXI. Estas informações permitem demonstrar como essa dinâmica de expansão, de especialização regional produtiva, consolida um conjunto de determinações territoriais. Entendidas as determinações como 'estado' e 'movimento' dos instrumentos de poder que se integram à apropriação capitalista do espaço em

1 Os dados cedidos pelo BNDES apresentam diferentes finalidades de desembolso, de acordo com a denominação estabelecida pelo Banco. 
direção à hegemonia e que, portanto, reúnem uma perspectiva de classe. O território é uma expressão de classe em suas formas de apropriação do espaço. "Expressam-se determinações territoriais como fundamentos das relações de classe na formação e apropriação do valor." (SOUZA e BORGES, 2017, p. 249).

A expressão espacial desta hegemonia, como determinação territorial, é a homogeneização da paisagem. Souza (2008) afirma que esta homogeneização representa um índice de diversidade produtiva, construído a partir de um modelo de entropia que sintetiza o avanço das culturas comerciais, como um movimento "geofágico" de consumo das terras e espacialidades diversas, sociais, econômicas, culturais e de domínios morfoclimáticos (cerrado, por exemplo) em direção à homogeneização. Para tal, utiliza-se o índice de homogeneização $(H)$ que possibilita expressar o avanço da territorialidade do agronegócio, como expressão espacial de suas relações de poder, neste caso, pelo setor sucroenergético. Neste sentido, essa homogeneização da paisagem representa uma homogeneização territorial, no sentido de uma imposição de práticas socioespaciais e de mudanças nas relações sociais, econômicas, técnico-produtivas, entre outras, aprofundando relações mercantis e financeiras na agricultura. Diante do exposto, para a consecução da análise, o trabalho foi estruturado em quatro partes considerando esta Introdução que reúne elementos metodológicos, seguida da análise dos desembolsos, da homogeneização da paisagem e por último as considerações finais.

Inicia-se a partir dos 'Desembolsos do BNDES por finalidade para o setor sucroenergético no estado de São Paulo', com o volume de desembolsos do BNDES por unidade da federação, de 2001 a 2008 e de 2009 a 2012, particularmente para o estado de São Paulo. Destaca-se que os períodos de análise estão segmentados tendo em vista que os dados do BNDES estão dispostos em 19 finalidades (BNDES, 2010) para o primeiro período e em seis finalidades, com outras categorizações, para o segundo período (BNDES, 2013a), impedindo sua agregação. Para identificar as determinações territoriais desses desembolsos, utilizou-se área colhida (hectares) e quantidade de cana-de-açúcar (toneladas) por unidade federativa e, com isso, obteve-se a quantidade de cana-deaçúcar por hectare, de 2000 a 2013, dados da Pesquisa Agrícola Municipal - IBGE - SIDRA (IBGE, 2017). Além disso, considerou-se a quantidade de cana-de-açúcar moída (toneladas), açúcar (toneladas) e etanol total (metros cúbicos), dados da União da Indústria de Cana-de-açúcar (UNICA, 2011) e do Ministério da Agricultura, Pecuária e Abastecimento (MAPA, 2013), disponíveis apenas para o período/safra de 2004/05 a 2012/13.

A seção 'Desembolsos por Mesorregião e Microrregião do estado de São Paulo' integra os dados disponibilizados pelo BNDES (2010 e 2013a), por município, microrregião e mesorregião, e correspondem aos valores liberados para o período de 2004 a 2012, sem identificação da finalidade. Nessa foram compilados os dados de área colhida (hectares) e quantidade de cana-de-açúcar (toneladas) por mesorregião, de 2004 a 2013 (IBGE, 2017), além da quantidade moída de cana-deaçúcar, para 2004/05 a 2012/2013, em UNICA (2011) e MAPA (2013) mediante solicitação. Nestas bases também se obteve a quantidade de agroindústrias sucroenergéticas (mesorregião) para as safras de 2004/05 a 2010/11, como indicadores de formação bruta de capital fixo (FBKF). Nos anos subsequentes, fez-se necessário utilizar a "Relação das unidades produtoras cadastradas no Departamento de Cana-de-açúcar e Agroenergia" do MAPA (2011, 2012 e 2013), para os anos de 2011 a 2013, a fim de completar o período. Além disso, buscou-se analisar as determinações sobre preços de terras, com os seguintes dados: Preço da terra agrícola com cana-de-açúcar em Reais (hectare), para os anos de 2004, 2008 e 2012, do Agrianual (2006 e 2014); e a Receita municipal média do período de 2004 a 2011, obtidos na base de Informações do Municípios Paulistas - IMP (SEADE, 2017). Todos os valores monetários foram corrigidos para valor constante de dezembro de 2017, a partir do Índice Geral de Preços - Disponibilidade Interna (IGP-DI), da Fundação Getúlio Vargas (FGV, 2017).

Por fim, apresenta-se o Índice de homogeneização (Índice de Theil) por mesorregião, tendo como referência a área agrícola colhida para culturas perenes e temporárias, de 2000 a 2012, dados do IBGE (2017). Este Índice também pode ser entendido como um coeficiente de Entropia, segundo Kon (1999). O trabalho de Souza e Cabero Diegues (2012) identifica o padrão de homogeneização do território rural paulista em comparação a Espanha, destacando o baixo índice de diversidade produtiva em relação ao país europeu, uma vez que quanto mais próximo de zero, menor a diversidade, ou seja, maior o padrão de homogeneização e consequentemente aumento da entropia que, embora homogêneo, apresenta maior desordem social, econômica e ambiental. 


\section{DESEMBOLSOS DO BNDES POR FINALIDADE PARA O SETOR SUCROENERGÉTICO NO ESTADO DE SÃO PAULO}

O BNDES desembolsou para o setor sucroenergético, no país, no período de 2001 a 2012, o total de $\mathrm{R} \$ 63,6$ bilhões, dos quais $44,8 \%$ ( $R \$ 28,5$ bilhões) no período de 2001 a 2008 e $55,2 \%$ ( $R \$ 35,1$ bilhões) no período de 2009 a 2012. Desse montante, o setor recebeu na macrorregião Sudeste $72,8 \%$ ( $R \$ 20,8$ bilhões), no primeiro período, e $55,5 \%$ ( $R \$ 19,5$ bilhões), no período subsequente. Ressalta-se que a procedência dos recursos do BNDES é, principalmente, governamental (BNDES, 2020). Para o ano de 2012, tem-se que os recursos governamentais compunham $83,1 \%$ da estrutura de capital (BNDES, 2013b), sendo: Tesouro Nacional (52,6\%); Fundo de Amparo ao Trabalhador (FAT) que é constituído pelo Fundo do Programa de Integração social (PIS) e do Programa de Formação do Patrimônio do Servidor Público (PASEP) e que, em conformidade com o parágrafo $1^{\circ}$ do artigo 239 da Constituição Federal, parte deste recurso deve ser destinado ao BNDES para o desenvolvimento econômico (BRASIL, 1988), estes recursos compõe o fundo denominado FAT/PISPASEP (27,2\%); outras fontes governamentais (3,3\%), como o Fundo da Marinha Mercante, Fundo Setorial do Audiovisual e Fundo Nacional sobre Mudança no Clima.

$\mathrm{Na}$ Figura 1, apresenta-se a distribuição espacial dos desembolsos totais de 2001 a 2012, identificando a concentração no eixo Centro-Sul, particularmente no estado de São Paulo. Dos estados da federação que receberam recursos no período de 2001 a 2008, guardam relevância: São Paulo com $65,7 \%$ ( $R \$ 18,7$ bilhões), Goiás com 10,53\% ( $R$ \$ 3 bilhões), Paraná com 7,94\% (R\$2,3 bilhões) e Minas Gerais com 7,2\% (R\$ 2,05 bilhões) do total país. Já, de 2009 a 2012, o setor sucroenergético do Paraná não faz parte dos quatro principais estados em volume captado no BNDES. Os principais estados são: São Paulo com 46,35\% (R\$ 16,3 bilhões), Goiás com $13,53 \%$ (R\$ 4,8 bilhões), Mato Grosso do Sul com 10,95\% (R\$ 3,6 bilhões) e Minas Gerais com 8,96\% ( $R$ \$ 3,148 bilhões) do total país.

Figura 1 - Desembolsos totais do BNDES, por estado brasileiro ao setor sucroenergético (2001-2012), em Reais constantes de 2017.

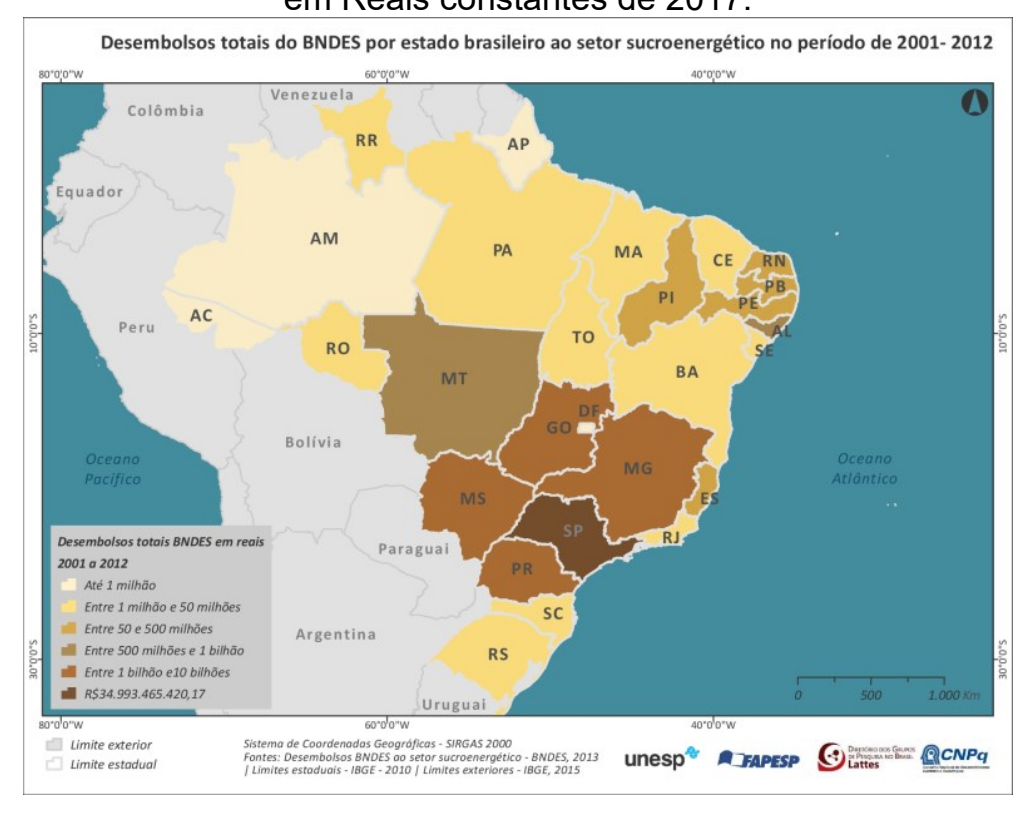

Para este último período, vale ressaltar que há recursos do BNDES que compreendem mais de um destino (unidade federativa), sendo denominado como 'Interestadual', somando $\mathrm{R} \$ 4,9$ bilhões, o que representa $14,01 \%$ do total, o que denota a gradual desconcentração espacial do setor no país. As maiores captações realizadas pelo setor sucroenergético ocorreram nos anos de 2007 e 2008, que juntos somam $R \$ 10,5$ bilhões (56,23\% do total do estado de São Paulo e $36,92 \%$ do total país), e de 2010 , com $\mathrm{R} \$ 5,77$ bilhões, o que equivale a $35,43 \%$ do total do estado de São Paulo e $16,42 \%$ do total do país.

O setor sucroenergético no estado de São Paulo captou em quase todos os tipos de finalidades de desembolso do BNDES, no período de 2001 a 2008, exceto para 'desenvolvimento tecnológico e

$\begin{array}{lllll}\text { Caminhos de Geografia } & \text { Uberlândia-MG } & \text { v. 21, n. } 76 & \text { Ago/2020 } & \text { p. 264-284 Página } 267\end{array}$


aquisição e recuperação de máquinas agrícolas' (Tabela 1). As principais finalidades de desembolso, nesse período, no país e estado de São Paulo, foram 'expansão', 'financiamento de compra de máquinas e serviços' e 'implantação'2. Juntas estas finalidades representam $92,73 \%$ ( $R \$ 26,4$ bilhões) do total de recursos para o setor no país e $91,39 \%$ ( $R \$ 17,08$ bilhões) do total do estado de São Paulo. Este volume do estado de São Paulo representa $64,66 \%$ do volume dessas três finalidades para o país.

Essas três finalidades contribuem para o aumento das áreas plantadas e moagem de cana-deaçúcar, bem como para o aumento da produção dos subprodutos açúcar e etanol. Além disso, essas finalidades tendem a impactar no aumento da produtividade do setor. Isso se coaduna a finalidade 'expansão' que foi de $\mathrm{R} \$ 4,7$ bilhões, equivalente a $25,32 \%$ do volume de recursos financeiros de todas as finalidades recebidas pelo setor no estado de São Paulo, enquanto a finalidade 'financiamento de compra de máquinas e serviços' corresponde a $41 \%$ ( $R \$ 7,67$ bilhões) e 'implantação' a $24,98 \%$ (R\$ 4,67 bilhões). É importante vincar que o processo de implantação, para os casos dos projetos financiados pelo BNDES, tem um tempo para atingir a produção máxima. Milanez, Barros e Faveret Filho (2008) estimaram que este tempo é de aproximadamente três anos para alcançar o total da capacidade produtiva.

Tabela 1 - Desembolsos do BNDES por finalidade para estado de São Paulo e macrorregião (2001 2008) (mil Reais).

\begin{tabular}{|c|c|c|c|c|c|}
\hline $\begin{array}{l}\text { Áreas de } \\
\text { Análise }\end{array}$ & $\begin{array}{l}\text { Aquis./Recup. } \\
\text { Maq. Agrícola }\end{array}$ & $\begin{array}{l}\text { Capital De } \\
\text { Giro }\end{array}$ & $\begin{array}{l}\text { Capitaliz. } \\
\text { Inst. }\end{array}$ & $\begin{array}{l}\text { Cartão } \\
\text { Bndes }\end{array}$ & $\begin{array}{l}\text { Desenvolvimento } \\
\text { Mercado Capitais }\end{array}$ \\
\hline Espirito Santo & 0,00 & 0,00 & 59,08 & 0,00 & 0,00 \\
\hline Minas Gerais & 0,00 & $17.909,80$ & $1.362,03$ & 105,51 & 0,00 \\
\hline Rio De Janeiro & 0,00 & 0,00 & 0,00 & 0,00 & 0,00 \\
\hline São Paulo & 0,00 & $192.471,83$ & $50.809,91$ & 523,04 & $281.718,96$ \\
\hline Total Sudeste & 0,00 & $210.381,63$ & $52.231,02$ & 628,55 & $281.718,96$ \\
\hline Total Centro Sul & 332,79 & $210.381,63$ & $53.517,12$ & $1.224,90$ & $281.718,96$ \\
\hline \multirow[t]{2}{*}{ Total País } & 332,79 & $229.666,02$ & $53.838,88$ & $1.369,30$ & $281.718,96$ \\
\hline & Social & Expansão & Maq./Serv. & Implantação & Meio Ambiente \\
\hline Espirito Santo & 0,00 & $8.040,04$ & $17.449,00$ & 0,00 & 0,00 \\
\hline Minas Gerais & $1.231,14$ & $546.338,01$ & $788.070,48$ & $551.278,46$ & 0,00 \\
\hline Rio De Janeiro & 0,00 & 0,00 & $5.267,26$ & 93,34 & 0,00 \\
\hline São Paulo & $1.064,64$ & $4.737 .380,21$ & 7.670.372,36 & 4.673.392,92 & $16.887,19$ \\
\hline Total Sudeste & $2.295,78$ & $5.291 .758,26$ & $8.481 .159,10$ & $5.224 .764,72$ & $16.887,19$ \\
\hline Total Centro Sul & $2.295,78$ & $7.103 .926,40$ & $10.194 .100,25$ & $8.244 .060,03$ & $21.625,32$ \\
\hline \multirow[t]{2}{*}{ Total País } & $2.295,78$ & $7.456 .122,72$ & $10.710 .135,92$ & $8.251 .915,40$ & $21.625,32$ \\
\hline & $\begin{array}{l}\text { Pós-Embarque- } \\
\text { Suppliers }\end{array}$ & $\begin{array}{c}\text { Pré- } \\
\text { Embarque- }\end{array}$ & $\begin{array}{l}\text { Racionaliza- } \\
\text { ção }\end{array}$ & $\begin{array}{l}\text { Reestrut. } \\
\text { Societária }\end{array}$ & Modernização \\
\hline Espirito Santo & 0,00 & 0,00 & 0,00 & 0,00 & 0,00 \\
\hline Minas Gerais & 0,00 & 0,00 & $22.283,64$ & 0,00 & $42.896,10$ \\
\hline Rio De Janeiro & 0,00 & 0,00 & 0,00 & 0,00 & 0,00 \\
\hline São Paulo & $165.186,73$ & $32.668,68$ & $188.960,42$ & $241.588,05$ & $359.637,54$ \\
\hline Total Sudeste & $165.186,73$ & $32.668,68$ & $211.244,06$ & $241.588,05$ & $402.533,64$ \\
\hline Total Centro Sul & $169.438,85$ & $32.668,68$ & $233.915,23$ & $241.588,05$ & $548.964,56$ \\
\hline \multirow[t]{2}{*}{ Total País } & $232.994,09$ & $39.376,79$ & $239.245,53$ & $241.588,05$ & $548.964,56$ \\
\hline & Refinanciamento & Relocalização & Social & Des. Tecnol. & Total \\
\hline Espirito Santo & 0,00 & 0,00 & 0,00 & 0,00 & $25.548,12$ \\
\hline Minas Gerais & 339,56 & $79.641,92$ & 0,00 & 0,00 & $2.051 .456,65$ \\
\hline Rio De Janeiro & 0,00 & 0,00 & 0,00 & 0,00 & $5.360,60$ \\
\hline São Paulo & $2.524,73$ & $89.243,79$ & $1.527,09$ & 0,00 & 18.705.958,11 \\
\hline Total Sudeste & $2.864,29$ & $168.885,71$ & $1.527,09$ & 0,00 & $20.788 .323,48$ \\
\hline Total Centro Sul & $3.614,67$ & $168.885,71$ & $3.018,04$ & 0,00 & 27.515.276,99 \\
\hline Total País & $3.614,67$ & $168.885,71$ & $3.018,04$ & $2.282,59$ & 28.488.991,12 \\
\hline
\end{tabular}

Nota: Em Reais constantes de 2017. Fonte: BNDES (2010).

\footnotetext{
2 Finalidade 'expansão' representa ampliação da capacidade produtiva, inclusive capacidade instalada. Finalidade 'financiamento de compra de máquinas e serviços' refere-se à reposição e ampliação da capacidade produtiva. Finalidade 'implementação' trata da instalação de novas unidade produtivas.
} 
Na Tabela 2, têm-se as finalidades de desembolsos do BNDES para o período de 2009 a 2012 . Para o período, o setor sucroenergético do estado de São Paulo da mesma forma captou em todas as finalidades, sendo as de maior destaque a 'fabricação de açúcar em bruto' com 34,98\% (R\$ 5,7 bilhões) do total do estado, 'cultivo de cana-de-açúcar' com 22,38\% (R\$ 3,6 bilhões), 'geração de energia elétrica' com 21,25\% (R\$ 3,46 bilhões) e 'fabricação de álcool' com 19,39\% (R\$ 3,2 bilhões). A geração de energia elétrica por agroindústrias sucroenergéticas permite suprir a demanda de seu processo industrial, bem como comercializar com distribuidoras-comercializadores de energia elétrica (SOUZA, 2002). Esta comercialização se iniciou em fins da década de 1980, mas atingiu expressividade nas unidades a partir de meados dos anos 1990. Segundo Souza (2002) e Belik e Vian (2002), a cogeração de energia elétrica, compreendida como uma estratégia de diversificação da produção, foi uma das práticas adotadas pelas empresas a partir da década de 1990, quando se deu o delineamento da nova dinâmica de competição no setor. Souza (2002, p. 224-225) aponta que o BNDES, em 2001, identificando a importância da cogeração, estabelece um "Programa de Apoio à Co-geração de Energia Elétrica a partir de resíduos da Cana-de-Açúcar". Essas finalidades (Tabela 2) contribuem para o aumento da produção e da produtividade do setor sucroenergético, assim como as finalidades analisadas no período de 2001 a 2008.

Tabela 2 - Desembolsos do BNDES por finalidade para estado de São Paulo e macrorregião (2009 2012) (mil Reais).

\begin{tabular}{|c|c|c|c|c|}
\hline Áreas de Análise & $\begin{array}{c}\text { Comércio Atacadista } \\
\text { De Açúcar }\end{array}$ & $\begin{array}{c}\text { Cultivo De } \\
\text { Cana-De-Açúcar }\end{array}$ & $\begin{array}{l}\text { Fabricação De Açúcar } \\
\text { De Cana Refinado }\end{array}$ & \\
\hline Espirito Santo & 136,19 & $22.582,13$ & 0,00 & \\
\hline Minas Gerais & $1.678,00$ & $619.026,14$ & $40.741,02$ & \\
\hline Rio De Janeiro & 203,56 & $5.511,89$ & 0,00 & \\
\hline São Paulo & $294.984,09$ & $3.644 .839,13$ & $31.997,74$ & \\
\hline Total Sudeste & $297.001,84$ & $4.291 .959,29$ & $72.738,76$ & \\
\hline Total Centro Sul & $302.030,79$ & $5.206 .038,71$ & $139.211,02$ & \\
\hline Total País & $338.893,10$ & $5.344 .203,76$ & $145.522,67$ & \\
\hline & $\begin{array}{l}\text { Fabricação De } \\
\text { Açúcar Em Bruto }\end{array}$ & $\begin{array}{c}\text { Fabricação De } \\
\text { Álcool }\end{array}$ & $\begin{array}{c}\text { Geração De Energia } \\
\text { Elétrica }\end{array}$ & Total \\
\hline Espirito Santo & 912,62 & $46.905,05$ & 0,00 & $70.535,98$ \\
\hline Minas Gerais & $467.402,14$ & $1.955 .499,41$ & $64.062,33$ & $3.148 .409,04$ \\
\hline Rio De Janeiro & $1.554,21$ & 0,00 & 0,00 & $7.269,66$ \\
\hline São Paulo & $5.697 .482,53$ & $3.157 .645,60$ & $3.460 .558,22$ & $16.287 .507,31$ \\
\hline Total Sudeste & $6.167 .351,50$ & $5.160 .050,06$ & $3.524 .620,55$ & 19.513.721,99 \\
\hline Total Centro Sul & $8.105 .609,48$ & $11.964 .778,24$ & $3.783 .945,46$ & $29.501 .613,70$ \\
\hline Total País & $8.919 .394,13$ & $16.476 .395,68$ & $3.917 .529,52$ & $35.141 .938,86$ \\
\hline
\end{tabular}

Este conjunto de dados de liberação vinculados à estrutura de processamento do setor sucroenergético, em verdade, determina a composição da formação bruta de capital fixo e seu grau de concentração econômica, ainda que apresente uma desconcentração espacial. De qualquer forma, os dados expressam uma expectativa de demanda de consumo, o que significa que a gradual fixação de capital, acelera a mudança da base de produção, produzindo uma reconversão produtiva com significativa velocidade, produzindo a substituição de culturas e as mudanças das relações sociais de produção no campo.

Assim, verifica-se que o maior crescimento na área colhida e quantidade produzida foram nos anos de 2006 a 2008, período de maior captação (Tabela 3). Os anos com os maiores níveis de quantidade produzida de cana-de-açúcar por hectare foram os de 2007 a 2010 , coincidindo com os maiores volumes de desembolsos do BNDES para o setor no estado de São Paulo.

Outra constatação relevante é que, se considerar o ano de 2013 em relação ao de 2000, nota-se o recrudescimento da área colhida de 2.484 .790 ha para 5.399 .235 ha e da quantidade produzida de cana-de-açúcar de 189.040 .000 toneladas para 434.079 .735 toneladas, representando uma variação de $117 \%$ e $130 \%$, respectivamente. Estes dados de variação indicam que a composição de FBKF não se consolida em processo de inovação tecnológica, visto que a variação de área e de produção não se alteram significativamente. No entanto, a expansão destas atividades concorre com mudanças estruturais no campo, visto que o processo de expansão da cultura em São Paulo, cujo domínio é expressivo, representa maior intensificação dos contratos de arrendamento, maior demanda por terra, mas sobretudo uma mudança social-estrutural no processo de produção. Tem-se com os

$\begin{array}{lllll}\text { Caminhos de Geografia } & \text { Uberlândia-MG } & \text { v. 21, n. } 76 & \text { Ago/2020 } & \text { p. 264-284 Página } 269\end{array}$


arrendamentos a alteração de sujeitos sociais na estrutura produtiva, uma vez que de agricultores estes sujeitos passam a atuar exclusivamente como rentistas, significando que sua única relação com o setor não é mediada pela produção, pela atividade agrícola, mas como proprietário rural, o que ratifica a lógica do rentismo à propriedade fundiária, a renda absoluta (HARVEY, 2006).

Tabela 3 - Área colhida (mil hectares), quantidade produzida (mil toneladas) e Quantidade produzida por hectare de cana-de-açúcar, de 2000 a 2013, no estado de São Paulo.

\begin{tabular}{|c|c|c|c|c|c|c|c|c|}
\hline Variáveis de Análise & & 2000 & 2001 & 2002 & 2003 & 2004 & 2005 & 2006 \\
\hline Área colhida (mil hectares) & (a) & 2.485 & 2.567 & 2.661 & 2.818 & 2.952 & 3.085 & 3.496 \\
\hline Variação (\%) & & & 3,32 & 3,65 & 5,89 & 4,76 & 4,50 & 13,33 \\
\hline Quantidade produzida (mil Ton.) & (b) & 189.040 & 198.932 & 212.707 & 227.981 & 239.528 & 254.810 & 289.299 \\
\hline Variação (\%) & & & 5,23 & 6,92 & 7,18 & 5,06 & 6,38 & 13,54 \\
\hline \multirow[t]{2}{*}{ Quantidade produzida por hectare } & $(\mathrm{b} / \mathrm{a})$ & 76,08 & 77,49 & 79,94 & 80,91 & 81,15 & 82,60 & 82,75 \\
\hline & & 2007 & 2008 & 2009 & 2010 & 2011 & 2012 & 2013 \\
\hline il hectares) & (a) & 3.890 & 4.531 & 4.781 & 4.987 & 5.206 & 5.150 & 5.399 \\
\hline Vari & & 11,29 & 16,46 & 5,53 & 4,29 & 4,40 & $-1,06$ & 4,83 \\
\hline Quantidade produzida (mil Ton.) & (b) & 329.096 & 386.061 & 408.451 & 426.572 & 427.365 & 406.153 & 434.080 \\
\hline Variação (\%) & & 13,76 & 17,31 & 5,80 & 4,44 & 0,19 & $-4,96$ & 6,88 \\
\hline Quantidade produzida por hectare & (b/a) & 84,59 & 85,21 & 85,42 & 85,54 & 82,09 & 78,86 & 80,40 \\
\hline
\end{tabular}

Na Tabela 4, tem-se a quantidade de cana-de-açúcar, açúcar e etanol total para o estado de São Paulo, da safra de 2004/05 a de 2012/13, período em que houve um crescimento, respectivamente, de $44,93 \%, 42,78 \%$ e $32,99 \%$, com alguns anos de decréscimo.

Tabela 4 - Quantidade de cana-de-açúcar (toneladas), de açúcar (toneladas) e etanol total (metros cúbicos), da safra de 2004/05 a de 201213, no estado de São Paulo.

\begin{tabular}{|c|c|c|c|c|c|}
\hline & $2004 / 05$ & $2005 / 06$ & $2006 / 07$ & $2007 / 08$ & \\
\hline $\begin{array}{l}\text { Cana-de-açúcar moída } \\
\text { (ton.) }\end{array}$ & 228.507 .270 & 241.840 .959 & 261.632 .157 & 294.210 .432 & \\
\hline Variação (\%) & & 5,84 & 8,18 & 12,45 & \\
\hline Açúcar (ton.) & 16.368 .947 & 16.702 .215 & 19.328.114 & 18.977.970 & \\
\hline Variação (\%) & & 2,04 & 15,72 & $-1,81$ & \\
\hline Etanol total $\left(\mathrm{m}^{3}\right)$ & 9.036 .775 & 9.905 .676 & 10.814 .973 & 13.246 .153 & \\
\hline \multirow[t]{2}{*}{ Variação (\%) } & & 9,62 & 9,18 & 22,48 & \\
\hline & $2008 / 09$ & $2009 / 10$ & $2010 / 11$ & $2011 / 2012$ & $2012 / 2013$ \\
\hline $\begin{array}{l}\text { Cana-de-açúcar moída } \\
\text { (ton.) }\end{array}$ & 349.994 .536 & 362.644 .755 & 361.169 .717 & 305.636 .316 & 331.173 .721 \\
\hline Variação (\%) & 18,96 & 3,61 & $-0,41$ & $-15,38$ & 8,36 \\
\hline Açúcar (ton.) & 20.115 .252 & 20.815 .404 & 23.506 .910 & 21.112 .970 & 23.371 .199 \\
\hline Variação (\%) & 5,99 & 3,48 & 12,93 & $-10,18$ & 10,70 \\
\hline Etanol total $\left(\mathrm{m}^{3}\right)$ & 16.758 .445 & 14.918 .631 & 15.422 .233 & 11.639 .325 & 12.018 .061 \\
\hline Variação (\%) & 26,52 & $-10,98$ & 3,38 & $-24,53$ & 3,25 \\
\hline
\end{tabular}

Assevera-se que esse crescimento (Tabelas 3 e 4) foi impactado pelos recursos do BNDES, mas também deve-se atentar que os recursos para investimento no setor podem ter outras origens, tais como recursos próprios (empresas e proprietários de terra), de bancos privados, de outras fontes públicas (SNCR - Sistema Nacional de Crédito Rural) e de abertura de capital das empresas.

\section{DESEMBOLSOS POR MESORREGIÃO E MICRORREGIÃO DO ESTADO DE SÃO PAULO}

Os desembolsos do BNDES para o setor sucroenergético, no estado de São Paulo, são apresentados por microrregião e mesorregião, com destaque para aqueles municípios com valores acima de $\mathrm{R} \$$ 200 milhões de desembolso, para o período de 2004 a 2008 e de 2009 a 2012 (Tabelas 5 e 6). 
Tabela 5 - Total de desembolsos do BNDES por municípios de destaque, microrregião e mesorregião (2004 - 2008), em mil Reais constantes de 2017.

\begin{tabular}{|c|c|c|c|}
\hline $\begin{array}{l}\text { Mesorregião/ Microrregião/ } \\
\text { Município }\end{array}$ & Total & $\begin{array}{l}\text { Mesorregião/ Microrregião/ } \\
\text { Município }\end{array}$ & Total \\
\hline Nova Independência & $282.905,61$ & Total São Paulo & $68.185,80$ \\
\hline Pereira Barreto & $538.102,98$ & Total Metropolitana de São Paulo & $68.196,18$ \\
\hline Total Andradina & $1.013 .218,63$ & Total Limeira & $150.739,65$ \\
\hline Valparaíso & $340.341,67$ & Piracicaba & $227.412,25$ \\
\hline Total Araçatuba & $501.600,25$ & Total Piracicaba & $399.007,68$ \\
\hline Brejo Alegre & $309.934,52$ & Total Rio Claro & $39.231,79$ \\
\hline Total Birigui & $520.570,75$ & Total Piracicaba & $588.979,12$ \\
\hline Total Araçatuba & $2.035 .389,64$ & Total Adamantina & $132.920,30$ \\
\hline Américo Brasiliense & $262.021,38$ & Ouro Verde & $229.901,27$ \\
\hline Nova Europa & $241.801,01$ & Total Dracena & $299.254,83$ \\
\hline Total Araraquara & $674.469,63$ & Narandiba & $508.645,79$ \\
\hline Total São Carlos & $82.000,69$ & Total Presidente Prudente & $664.224,55$ \\
\hline Total Araraquara & $756.470,32$ & Total Presidente Prudente & $1.096 .399,68$ \\
\hline Paraguaçu Paulista & $241.580,57$ & Total Barretos & $147.749,81$ \\
\hline Quatá & $388.856,67$ & Total Batatais & $166.498,89$ \\
\hline Tarumã & $347.582,47$ & Total Franca & $14.661,09$ \\
\hline Total Assis & $1.178 .246,89$ & Total Ituverava & $35.944,40$ \\
\hline Total Ourinhos & $74.041,17$ & Total Jaboticabal & $358.055,35$ \\
\hline Total Assis & $1.252 .288,07$ & Pradópolis & $233.024,61$ \\
\hline Total Avaré & $30.261,79$ & Total Ribeirão Preto & $684.071,98$ \\
\hline Total Bauru & $348.817,00$ & Guaíra & $428.093,95$ \\
\hline São Manuel & $318.008,46$ & Morro Agudo & $297.105,21$ \\
\hline Total Botucatu & $322.009,90$ & Orlândia & $261.686,54$ \\
\hline Macatuba & $248.447,90$ & São Joaquim da Barra & $363.623,33$ \\
\hline Total Jaú & $481.785,30$ & Total São Joaquim da Barra & $1.381 .073,06$ \\
\hline Promissão & $365.179,26$ & Total Ribeirão Preto & $2.788 .054,59$ \\
\hline Total Lins & $454.268,28$ & Total Auriflama & $54.172,13$ \\
\hline Total Bauru & $1.637 .142,29$ & Ariranha & $267.686,59$ \\
\hline Total Campinas & $162.003,33$ & Catanduva & $447.805,71$ \\
\hline Total Moji Mirim & $38.490,66$ & Total Catanduva & $902.539,83$ \\
\hline Pirassununga & $267.811,40$ & Total Fernandópolis & $54.038,58$ \\
\hline Total Pirassununga & $310.673,51$ & Total Jales & 173.318,21 \\
\hline Total São João da Boa Vista & $104.052,09$ & Monções & $207.417,72$ \\
\hline Total Campinas & $615.219,58$ & Total Nhandeara & $386.923,04$ \\
\hline Total Itapetininga & $63.462,75$ & Novo Horizonte & $394.662,70$ \\
\hline Total Itapeva & 967,51 & Total Novo Horizonte & $439.535,49$ \\
\hline Total Tatuí & $44.557,04$ & José Bonifácio & $335.655,09$ \\
\hline Total Itapetininga & $108.987,30$ & Planalto & $205.085,61$ \\
\hline Total Bragança & 160,23 & Total São José do Rio Preto & 1.418.778,08 \\
\hline Total Jundiaí & 53,73 & Total Votuporanga & $167.193,94$ \\
\hline Total Sorocaba & $7.592,92$ & Total São José do Rio Preto & $3.596 .499,30$ \\
\hline Total Macro Metropolitana Paulista & $7.806,87$ & Total Guaratinguetá & 123,93 \\
\hline Total Marília & $17.028,52$ & Total São José dos Campos & 129,81 \\
\hline Total Tupã & $178.637,05$ & Total Vale do Paraíba Paulista & 253,75 \\
\hline Total Marília & $203.472,44$ & Diversos Municípios & $323.705,41$ \\
\hline Total Santos & 10,38 & Total São Paulo & $15.078 .864,55$ \\
\hline
\end{tabular}

$\mathrm{Na}$ Tabela 5 é possível identificar 28 municípios com recursos do BNDES superiores a $\mathrm{R} \$ 200$ milhões, dos quais 8 municípios com mais de $R \$ 350$ milhões, com destaque para Pereira Barreto (R\$ 538 milhões), Narandiba (R\$ 508,65 milhões), Catanduva (R\$ 447,8 milhões) e Guaíra (R\$ 428,09 milhões), no período de 2004 a 2008. Das 63 microrregiões do estado, 49 têm recursos do BNDES para o setor, com destaque para a microrregião de São José do Rio Preto ( $R$ \$ 1,42 bilhões), São Joaquim da Barra ( $R$ \$ 1,38 bilhões), Assis ( $R$ \$ 1,18 bilhões) e Andradina ( $R$ \$ 1,03 bilhões). Das 15 mesorregiões do estado de São Paulo, todas, exceto Litoral Sul Paulista, têm desembolsos, das quais seis têm desembolsos acima de $R \$ 1$ bilhão, sendo São José do Rio Preto ( $R \$ 3,596$ bilhões), Ribeirão Preto ( $R$ \$ 2,79 bilhões), Araçatuba ( $R$ \$ 2,04 bilhões), Bauru ( $R$ \$ 1,64 bilhões), Assis ( $R$ \$ 1,25 bilhões) e Presidente Prudente ( $R \$ 1,096$ bilhões). À exceção de Ribeirão Preto, todas as demais áreas se colocam como novas de cultivo, de expansão espacial do setor, levando em conta que, a lógica de ocupação das mesmas, sempre estiveram marcadas por cultivos de pastagem e 
citrícola (São José do Rio Preto), pastagem e silvicultura (Bauru) e pastagem (Araçatuba, Assis e Presidente Prudente).

No período de 2009 a 2012, além dos desembolsos para "diversos municípios" (R\$ 323,7 milhões), há 26 municípios com desembolsos acima de $R \$ 200$ milhões, dos quais nove com desembolsos acima de $R \$ 350$ milhões (Tabela 6), sendo os principais São Paulo ( $R$ \$ 843,35 milhões), Mirante do Paranapanema ( $R$ \$ 582,74 milhões), Guaíra ( $R$ \$ 510,54 milhões), Barra Bonita ( $R$ \$ 492,28 milhões) e Serrana ( $R$ \$ 461,48 milhões). Vale frisar que o município de São Paulo tem a sede administrativa de agroindústrias sucroenergéticas e não possui área destinada à produção de cana-de-açúcar para indústria.

Tabela 6 - Total de desembolsos do BNDES por municípios de destaque, microrregião e mesorregião (2009 - 2012), em Reais constantes de 2017.

\begin{tabular}{|c|c|c|c|}
\hline $\begin{array}{l}\text { Mesorregião/ Microrregião/ } \\
\text { Município }\end{array}$ & Total & $\begin{array}{c}\text { Mesorregião/ Microrregião/ } \\
\text { Município }\end{array}$ & Total \\
\hline Andradina & $255.732,07$ & Total São Paulo & $843.348,51$ \\
\hline Total Andradina & $415.446,53$ & Total Metropolitana de São Paulo & $844.427,28$ \\
\hline Valparaíso & $300.917,34$ & Total Limeira & $69.520,06$ \\
\hline Total Araçatuba & $377.424,58$ & Total Piracicaba & $220.470,55$ \\
\hline Total Birigui & $382.388,53$ & Total Rio Claro & $181.717,03$ \\
\hline Total Araçatuba & $1.175 .259,64$ & Total Piracicaba & $471.707,64$ \\
\hline Total Araraquara & $353.992,51$ & Total Adamantina & $62.397,32$ \\
\hline Total São Carlos & $122.877,88$ & Total Dracena & $53.586,74$ \\
\hline Total Araraquara & $476.870,39$ & Mirante do Paranapanema & $582.740,22$ \\
\hline Paraguaçu Paulista & $240.927,42$ & Total Presidente Prudente & $989.805,98$ \\
\hline Quatá & $281.508,76$ & Total Presidente Prudente & $1.105 .790,04$ \\
\hline Tarumã & $279.928,94$ & Colina & $217.617,59$ \\
\hline Total Assis & $921.161,34$ & Total Barretos & $254.440,19$ \\
\hline Ipaussu & $270.492,90$ & Batatais & $257.501,62$ \\
\hline Total Ourinhos & $340.787,63$ & Total Batatais & $281.384,95$ \\
\hline Total Assis & $1.261 .948,97$ & Patrocínio Paulista & $215.456,33$ \\
\hline Cerqueira César & $343.499,29$ & Total Franca & $222.538,25$ \\
\hline Total Avaré & $465.029,57$ & Buritizal & $215.815,80$ \\
\hline lacanga & $240.200,73$ & Total Ituverava & $255.021,76$ \\
\hline Lençóis Paulista & $318.676,26$ & Guariba & $387.534,64$ \\
\hline Total Bauru & $593.981,54$ & Pitangueiras & $404.113,89$ \\
\hline São Manuel & $265.460,74$ & Total Jaboticabal & $1.422 .246,64$ \\
\hline Total Botucatu & $282.543,35$ & Serrana & $461.483,62$ \\
\hline Barra Bonita & $492.283,55$ & Sertãozinho & $292.311,30$ \\
\hline Total Jaú & $788.989,60$ & Total Ribeirão Preto & $1.199 .379,93$ \\
\hline Total Lins & $108.637,66$ & Guaíra & $510.544,87$ \\
\hline Total Bauru & $2.239 .181,72$ & São Joaquim da Barra & $239.834,40$ \\
\hline Total Amparo & 75,70 & Total São Joaquim da Barra & $933.917,62$ \\
\hline Total Campinas & $89.157,98$ & Total Ribeirão Preto & $4.568 .929,35$ \\
\hline Total Moji Mirim & $13.363,03$ & Total Auriflama & $19.452,72$ \\
\hline Total Pirassununga & $218.083,79$ & Ariranha & $233.623,16$ \\
\hline Total São João da Boa Vista & $73.212,13$ & Total Catanduva & $506.931,32$ \\
\hline Total Campinas & $393.892,63$ & Meridiano & $429.357,55$ \\
\hline Total Capão Bonito & 431,33 & Total Fernandópolis & $438.537,01$ \\
\hline Total Itapetininga & $174.314,32$ & Total Jales & $97.898,58$ \\
\hline Total Itapeva & $3.957,98$ & Sebastianópolis do Sul & $371.203,88$ \\
\hline Total Tatuí & $29.387,55$ & Total Nhandeara & $400.135,84$ \\
\hline Total Itapetininga & $208.091,18$ & Total Novo Horizonte & $140.930,07$ \\
\hline Total Bragança Paulista & 230,21 & Total São José do Rio Preto & $568.604,35$ \\
\hline Total Jundiaí & 180,69 & Total Votuporanga & $20.745,31$ \\
\hline Total Sorocaba & $3.725,30$ & Total São José do Rio Preto & $2.193 .235,20$ \\
\hline Total Macro Metropolitana Paulista & $4.136,20$ & Total Bananal & 92,11 \\
\hline Total Marília & $3.393,92$ & Total Guaratinguetá & $4.623,48$ \\
\hline Total Tupã & $25.909,22$ & Total Paraibuna/Paraitinga & 550,47 \\
\hline Total Marília & $29.303,14$ & Total São José dos Campos & 396,26 \\
\hline Total Osasco & 758,94 & Total Vale do Paraíba Paulista & $5.662,31$ \\
\hline Total Santos & 319,83 & Diversos municípios & $1.309 .236,10$ \\
\hline São Paulo & $843.348,51$ & Total São Paulo & $16.287 .671,80$ \\
\hline
\end{tabular}

Nota: Apresentação dos municípios com desembolsos acima de R\$ 200 milhões. Fonte: BNDES (2013a). 
Nesse período, das 63 microrregiões do estado de São Paulo, 54 têm desembolsos, seis a mais em relação ao período de 2004 a 2008. Das 54 microrregiões apenas duas apresentam desembolsos acima de $R \$ 1$ bilhão, são elas: Jaboticabal (R\$ 1,42 milhões) e Ribeirão Preto (R\$ 1,199 milhões). $\mathrm{Na}$ escala mesorregional, todas têm desembolsos do BNDES, exceto Litoral Sul Paulista, e evidenciase que as mesmas mesorregiões observadas no período de 2004 a 2008 apresentam os maiores volumes de recursos: Ribeirão Preto ( $R$ \$ 4,57 bilhões), Bauru (R\$ 2,24 bilhões), São José do Rio Preto (R\$ 2,19 bilhões), Assis (R\$ 1,26 bilhões), Araçatuba (R\$ 1,175 bilhões) e Presidente Prudente (R\$ 1,105 bilhões). Nas Figuras 2 e 3, observa-se a distribuição desses recursos por mesorregião. Destaca-se que a concentração dos recursos nas áreas de expansão do setor no Oeste e Centro paulista e a redução dos recursos nas áreas de antiga produção (Piracicaba e Campinas), com exceção de Ribeirão Preto, que concentra matrizes de usinas e parque industrial produtivo do setor. Destaca-se, nesse conjunto, o crescimento setorial de São José do Rio Preto que apresenta um volume significativo de inversão de recursos e alocação de usinas.

Figura 2 - Desembolsos totais, setor sucroenergético, por mesorregião do estado de São Paulo (2004-2008) em Reais constantes de 2017.

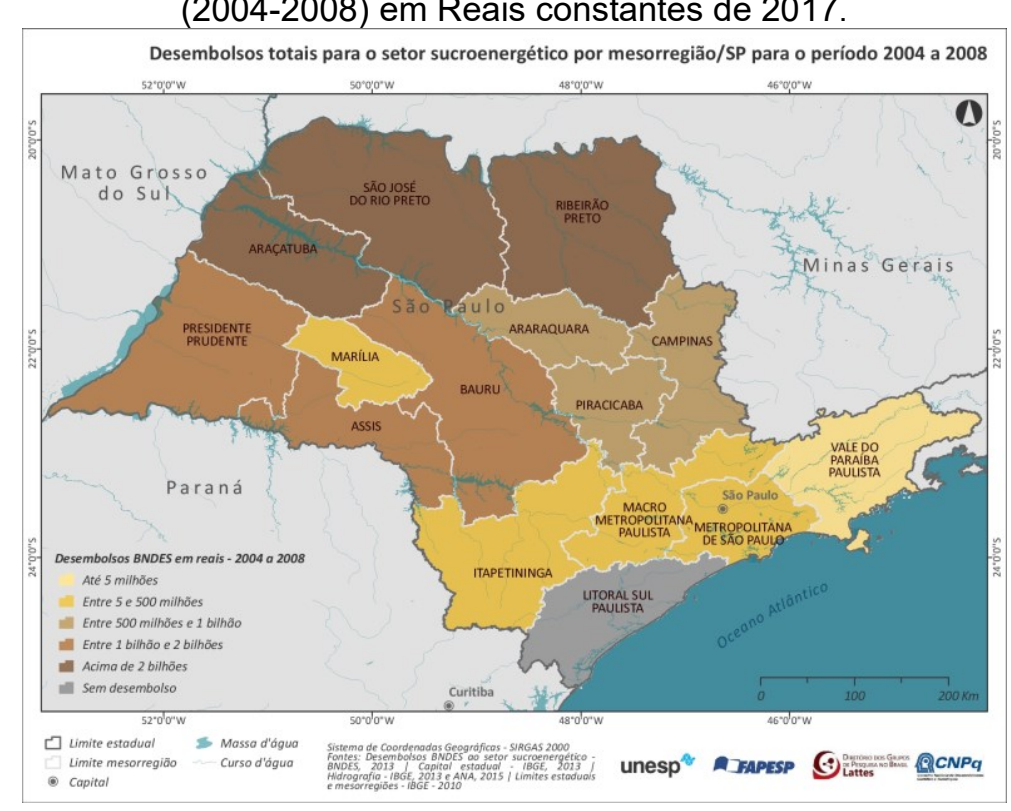

Ao verificar com minúcia os dois períodos (2004 a 2008 e 2009 a 2012), o estado de São Paulo detém $\mathrm{R} \$ 31,37$ bilhões de desembolsos e as seis mesorregiões de destaque somam $\mathrm{R} \$ 24,95$ bilhões, que representam 79,54\%. O volume de desembolso é de $R \$ 3,21$ bilhões para Araçatuba, $R \$$ 2,51 bilhões para Assis, R\$ 3,876 bilhões para Bauru, R\$ 2,2 bilhões para Presidente Prudente, R\$ 7,36 bilhões em Ribeirão Preto e R 5,79 bilhões em São José do Rio Preto, soma dos dados das Tabelas 5 e 6.

Quanto aos desembolsos, estes possivelmente favoreceram a instalação de agroindústrias sucroenergéticas (Tabela 7), visto que, para todas as mesorregiões com maior volume de desembolso, há aumento das unidades ao longo do período de 2004/05 ao ano de 2013. A mesorregião de Ribeirão Preto atingiu o número de 40 unidades, entre 2009/10 e 2010/11, maior número dentre as mesorregiões, caindo para 35 unidades em 2013. Importante mencionar que os aumentos das unidades nas mesorregiões de: São José do Rio Preto de 18 para 28; Presidente Prudente de 7 para 14 unidades; Araçatuba de 12 para 19 unidade; Assis de 11 para 16; e Bauru de 12 para 17 agroindústrias sucroenergéticas. Ressalta-se que estas cinco mesorregiões detêm os dez municípios com maior captação e que possuem os municípios com variação positiva no preço da terra, acima de $24 \%$. 
Figura 3 - Desembolsos totais, setor sucroenergético, por mesorregião do estado de São Paulo (2009 - 2012), em Reais constantes de 2017.

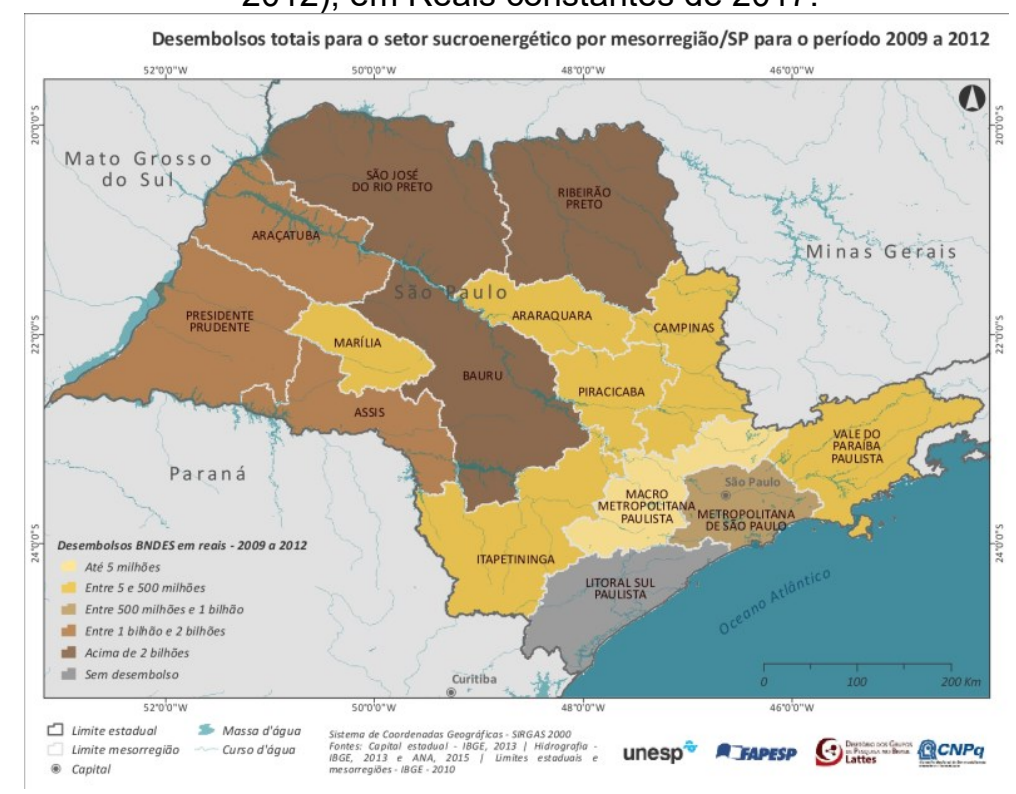

Tabela 7 - Total de agroindústrias sucroenergéticas por mesorregião e estado de São Paulo, para safra de 2004/05 a 2010/11 e anos de 2011 a 2013.

\begin{tabular}{lrrrrr}
\hline Mesorregião/Estado & $\mathbf{2 0 0 4 / 0 5}$ & $\mathbf{2 0 0 5 / 0 6}$ & $\mathbf{2 0 0 6 / 0 7}$ & $\mathbf{2 0 0 7 / 0 8}$ & $\mathbf{2 0 0 8 / 0 9}$ \\
\hline Araçatuba & 12 & 12 & 14 & 15 & 20 \\
Araraquara & 9 & 9 & 10 & 10 & 8 \\
Assis & 11 & 14 & 13 & 17 & 18 \\
Bauru & 12 & 12 & 17 & 18 & 19 \\
Campinas & 13 & 13 & 13 & 13 & 12 \\
Itapetininga & 4 & 3 & 3 & 4 & 5 \\
Marília & 0 & 0 & 0 & 0 & 1 \\
Piracicaba & 12 & 11 & 13 & 13 & 16 \\
Presidente Prudente & 7 & 7 & 11 & 11 & 15 \\
Ribeirão Preto & 38 & 38 & 38 & 38 & 37 \\
São José do Rio Preto & 18 & 20 & 22 & 26 & 28 \\
Vale do Paraíba Paulista & 0 & 0 & 0 & 0 & 1 \\
\hline Total São Paulo & 136 & 139 & 154 & 165 & 180 \\
\hline Araçatuba & $2009 / 10$ & $\mathbf{2 0 1 0 / 1 1}$ & $\mathbf{2 0 1 1}$ & $\mathbf{2 0 1 2}$ & $\mathbf{2 0 1 3}$ \\
\hline Araraquara & 20 & 20 & 19 & 19 & 19 \\
Assis & 9 & 9 & 8 & 8 & 8 \\
Bauru & 20 & 19 & 18 & 17 & 16 \\
Campinas & 21 & 20 & 19 & 18 & 17 \\
Itapetininga & 12 & 13 & 11 & 11 & 10 \\
Marília & 5 & 5 & 5 & 5 & 4 \\
Piracicaba & 1 & 1 & 1 & 1 & 1 \\
Presidente Prudente & 16 & 16 & 16 & 12 & 11 \\
Ribeirão Preto & 16 & 18 & 16 & 14 & 14 \\
São José do Rio Preto & 40 & 40 & 36 & 36 & 35 \\
Vale do Paraíba Paulista & 29 & 29 & 32 & 29 & 28 \\
\hline Total São Paulo & 1 & 1 & 1 & 0 & 0 \\
\hline
\end{tabular}

Fonte: UNICA (2011) e MAPA (2011, 2012 e 2013).

Quanto à área colhida e quantidade produzida de cana-de-açúcar (Tabela 8), nota-se que as mesorregiões com maior crescimento são as seis mesorregiões com maior volume de desembolsos mais a de Araraquara. Destas, as que apresentaram maior crescimento na área colhida de cana-deaçúcar, no período de 2004 a 2008, são Presidente Prudente $(326,44 \%)$, São José do Rio Preto $(210,6 \%)$, Araçatuba $(128,04 \%)$, visto que Ribeirão Preto, Bauru e Assis cresceram menos, respectivamente, $37,63 \%, 77,76 \%$ e $66,10 \%$. A mesma tendência é observada para a quantidade

$\begin{array}{lllll}\text { Caminhos de Geografia } \quad \text { Uberlândia-MG } & \text { v. 21, n. } 76 & \text { Ago/2020 } & \text { p. 264-284 Página } 274\end{array}$


produzida de cana-de-açúcar, sendo o maior crescimento para Presidente Prudente (292,64\%), São José do Rio Preto $(207,78 \%)$ e Araçatuba $(126,61 \%)$. O processo de expansão produtiva destas regiões, que passaram a ser integradas e objeto específico da atividade do setor, tem respaldo central no comportamento dos preços da terra e nos arrendamentos.

Tabela 8 - Área colhida (mil hectares) e quantidade produzida (mil toneladas) de cana-de-açúcar, em 2004 e 2013, nas mesorregiões do estado de São Paulo, com desembolso do BNDES.

\begin{tabular}{|c|c|c|c|c|}
\hline & Mesorregiões & 2004 & 2013 & Variação (\%) \\
\hline \multirow{14}{*}{$\begin{array}{l}\text { Área Colhida (mil } \\
\text { ha) }\end{array}$} & Araçatuba & 223 & 509 & 128,04 \\
\hline & Araraquara & 266 & 382 & 43,68 \\
\hline & Assis & 203 & 338 & 66,10 \\
\hline & Bauru & 351 & 625 & 77,76 \\
\hline & Campinas & 197 & 249 & 26,36 \\
\hline & Itapetininga & 36 & 73 & 105,15 \\
\hline & Macro Metropolitana Paulista & 19 & 23 & 19,37 \\
\hline & Marília & 8 & 71 & 809,54 \\
\hline & Metropolitana de São Paulo & & 0,01 & \\
\hline & Piracicaba & 253 & 313 & 23,85 \\
\hline & Presidente Prudente & 123 & 525 & 326,44 \\
\hline & Ribeirão Preto & 958 & 1.319 & 37,63 \\
\hline & São José do Rio Preto & 312 & 970 & 210,60 \\
\hline & Vale do Paraíba Paulista & 1 & 3 & 74,61 \\
\hline \multirow{14}{*}{$\begin{array}{l}\text { Quant. produzida } \\
\text { (mil Ton.) }\end{array}$} & Araçatuba & 17.710 & 40.132 & 126,61 \\
\hline & Araraquara & 20.783 & 32.019 & 54,06 \\
\hline & Assis & 16.618 & 27.130 & 63,26 \\
\hline & Bauru & 28.206 & 50.841 & 80,25 \\
\hline & Campinas & 16.036 & 21.411 & 33,52 \\
\hline & Itapetininga & 2.926 & 6.197 & 111,79 \\
\hline & Macro Metropolitana Paulista & 1.344 & 1.864 & 38,69 \\
\hline & Marília & 589 & 5.433 & 822,95 \\
\hline & Metropolitana de São Paulo & - & 0.012 & * \\
\hline & Piracicaba & 20.091 & 24.050 & 19,71 \\
\hline & Presidente Prudente & 9.798 & 38.469 & 292,64 \\
\hline & Ribeirão Preto & 79.633 & 107.028 & 34,40 \\
\hline & São José do Rio Preto & 25.743 & 79.232 & 207,78 \\
\hline & Vale do Paraíba Paulista & 52 & 274 & 425,92 \\
\hline
\end{tabular}

Nas Figuras 4 e 5, apresenta-se o comportamento das áreas colhidas e produzidas, denotando a alavancagem do setor a partir de recursos governamentais.

Figura 4 - Área colhida e quantidade produzida de cana-de-açúcar, mesorregião-SP, 2004.

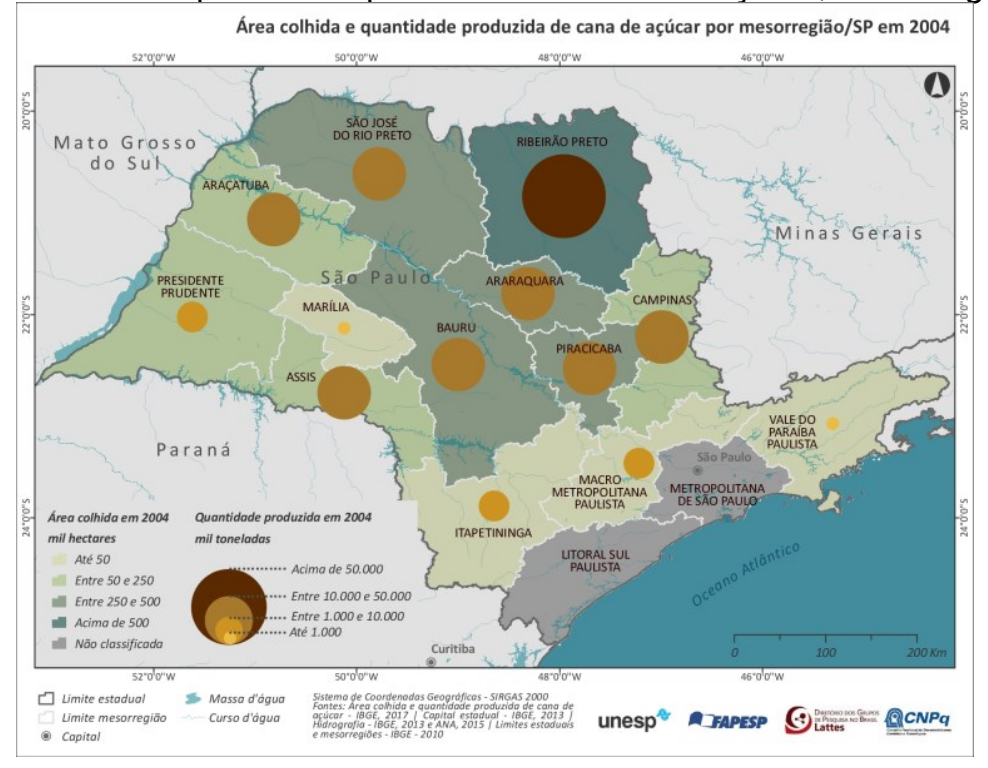


Figura 5 - Área colhida e quantidade produzida de cana-de-açúcar, mesorregião-SP, 2013

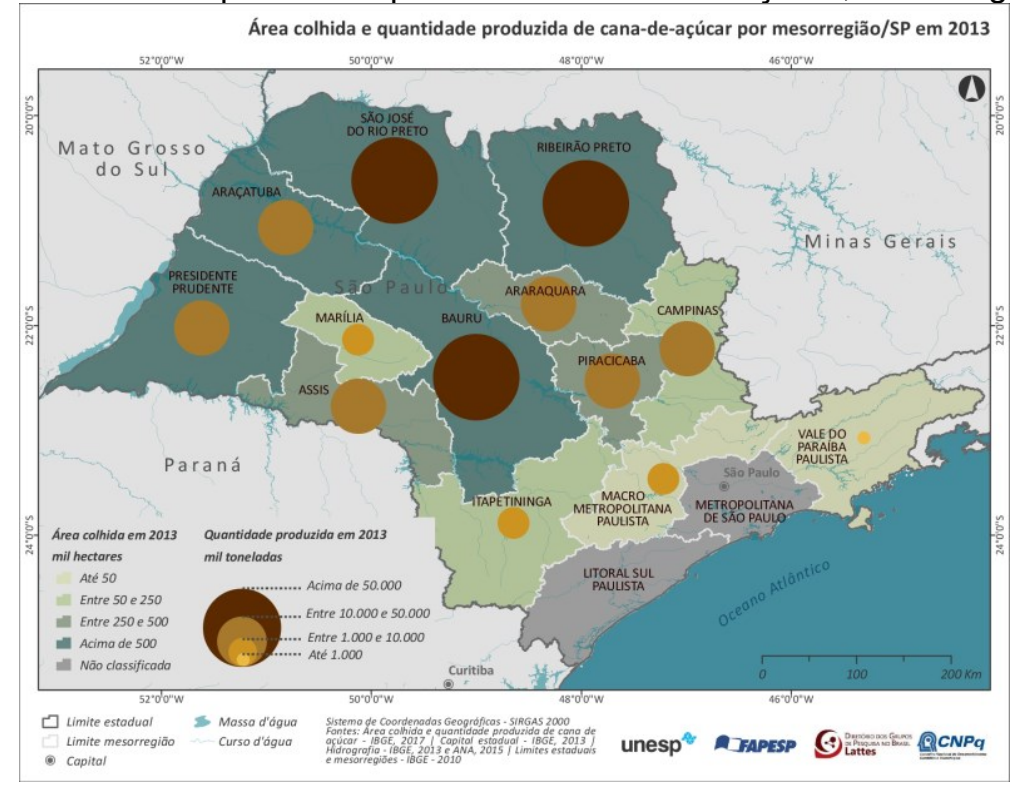

Na Figura 6, demonstra-se a variação da área colhida, com padrões superiores a 50\%, e da área produzida que atinge patamares de até $500 \%$, denotando o incremento de insumos e variedade em determinadas mesorregiões do estado de São Paulo. Ao dar relevo aos municípios em que o setor recebeu mais de $\mathrm{R} \$ 350$ milhões de desembolso do BNDES, verifica-se a variação positiva no preço médio da terra agrícola com cana-de-açúcar, de 2012 em relação a 2004, para todos, exceto para Guariba que praticamente manteve o valor, mas que apresenta também os maiores preços da terra dos municípios selecionados (Tabela 10).

Figura 6 - Variação da área colhida e quantidade produzida de cana-de-açúcar, mesorregião-SP, 2004/2013.

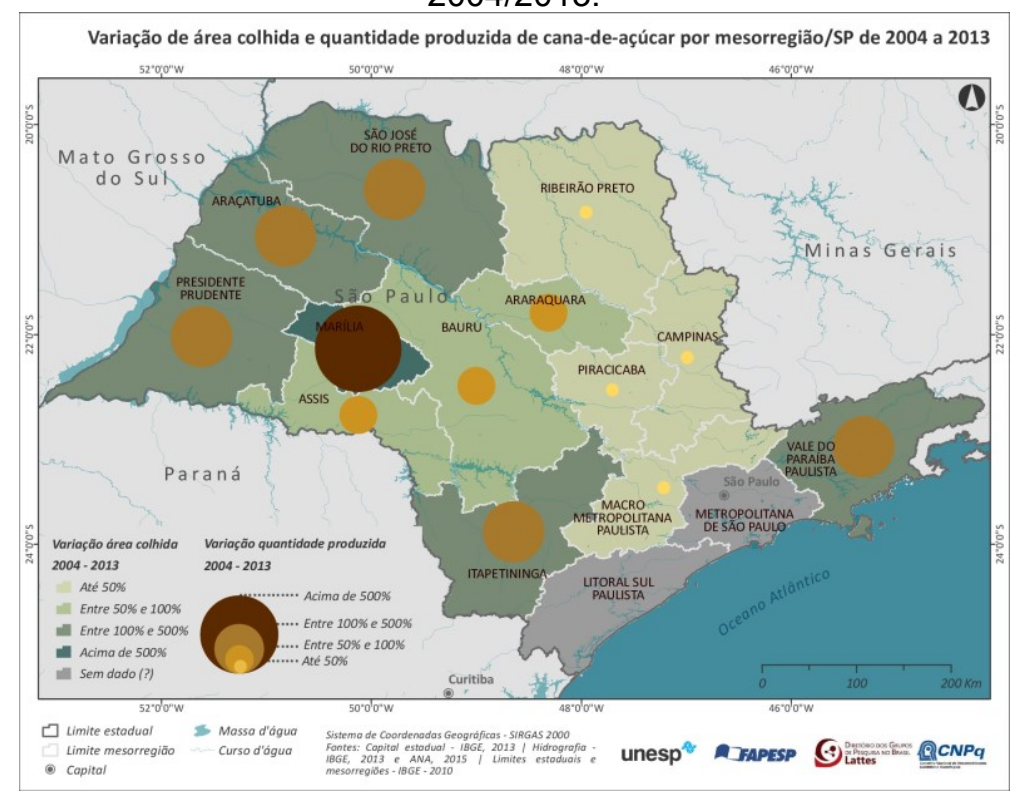

Os impactos do BNDES também se desdobram na variação da moagem de cana-de-açúcar, no período de 2004/05 a 2012/13, no estado de São Paulo que foi de $44,93 \%$, com destaque para as mesorregiões de Presidente Prudente $(158,75 \%)$, Araçatuba $(110,88 \%)$ e São José do Rio Preto $(98,02 \%)$. Assis, Bauru e Ribeirão Preto são as outras mesorregiões com maior volume de recursos

$\begin{array}{lllll}\text { Caminhos de Geografia } & \text { Uberlândia-MG } & \text { v. 21, n. } 76 & \text { Ago/2020 } & \text { p. 264-284 Página } 276\end{array}$


do BNDES, mas que apresentaram uma variação menor do que 40\% (Tabela 9). Na Figura 7 , apresenta-se a variação entre as safras de 2004/2013 e a relação significativa entre recursos e moagem, sobretudo nas áreas de expansão, o oeste paulista.

Tabela 9 - Total de moagem de cana-de-açúcar (toneladas) por mesorregião e estado de São Paulo,

\begin{tabular}{|c|c|c|c|c|c|}
\hline Mesorregião/Estado & $2004 / 05$ & $2005 / 06$ & $2006 / 07$ & $2007 / 08$ & \\
\hline Araçatuba & 14.314 .027 & 15.114 .483 & 17.709 .693 & 22.822 .072 & \\
\hline Araraquara & 13.420 .445 & 14.522 .106 & 14.662 .695 & 16.076 .356 & \\
\hline Assis & 16.834 .641 & 15.874.909 & 18.068.755 & 23.152 .432 & \\
\hline Bauru & 27.896 .535 & 27.250 .586 & 29.741 .724 & 34.308 .032 & \\
\hline Campinas & 11.691 .158 & 12.718 .318 & 14.207 .448 & 16.255 .762 & \\
\hline Itapetininga & 2.048.382 & 2.136 .567 & 2.325 .380 & 3.503 .209 & \\
\hline Marília & 0 & 0 & 0 & 0 & \\
\hline Piracicaba & 19.169.896 & 19.114.125 & 19.761 .836 & 22.403 .498 & \\
\hline Presidente Prudente & 7.653 .792 & 8.294 .972 & 11.612 .594 & 12.308 .937 & \\
\hline Ribeirão Preto & 82.891 .604 & 91.255 .327 & 90.881 .532 & 93.876 .387 & \\
\hline São José do Rio Preto & 32.586 .790 & 35.559 .566 & 42.660 .500 & 49.503 .747 & \\
\hline Vale do Paraíba Paulista & 0 & 0 & 0 & 0 & \\
\hline Total São Paulo & 228.507 .270 & 241.840 .959 & 261.632 .157 & 294.210 .432 & \\
\hline Mesorregião/Estado & $2008 / 09$ & $2009 / 10$ & $2010 / 11$ & $2011 / 2012$ & $2012 / 2013$ \\
\hline Araçatuba & 31.998 .580 & 35.209 .495 & 36.053 .767 & 27.368 .438 & 30.185 .555 \\
\hline Araraquara & 16.415 .481 & 17.428.991 & 16.186.598 & 13.531 .009 & 15.045 .685 \\
\hline Assis & 24.755.716 & 27.803 .498 & 25.758 .770 & 23.666 .235 & 23.339.132 \\
\hline Bauru & 41.732 .227 & 40.589 .430 & 41.159 .794 & 34.986 .790 & 38.076 .819 \\
\hline Campinas & 18.007 .875 & 16.609 .825 & 17.205 .384 & 15.309 .006 & 17.155 .968 \\
\hline Itapetininga & 5.884 .889 & 4.355 .039 & 3.512 .724 & 3.400 .259 & 3.219 .210 \\
\hline Marília & 3.279 .631 & 4.364 .128 & 4.038.517 & 3.853 .760 & 3.933 .277 \\
\hline Piracicaba & 24.160 .034 & 23.797.737 & 21.961 .710 & 19.911 .900 & 20.180 .353 \\
\hline Presidente Prudente & 15.866 .700 & 21.330 .735 & 22.085 .680 & 20.924 .930 & 19.803 .879 \\
\hline Ribeirão Preto & 97.751 .131 & 101.885.496 & 105.673 .456 & 86.571 .897 & 95.704 .901 \\
\hline São José do Rio Preto & 70.142 .272 & 69.201 .922 & 67.216 .170 & 56.052 .444 & 64.528 .942 \\
\hline Vale do Paraíba Paulista & 0 & 68.459 & 317.147 & 59.648 & 0 \\
\hline Total São Paulo & 349.994 .536 & 362.644 .755 & 361.169 .717 & 305.636 .316 & 331.173 .721 \\
\hline
\end{tabular}

Figura 7 - Quantidade (ton.) e Variação (\%) da Moagem de cana-de-açúcar, mesorregião-SP, 2004-

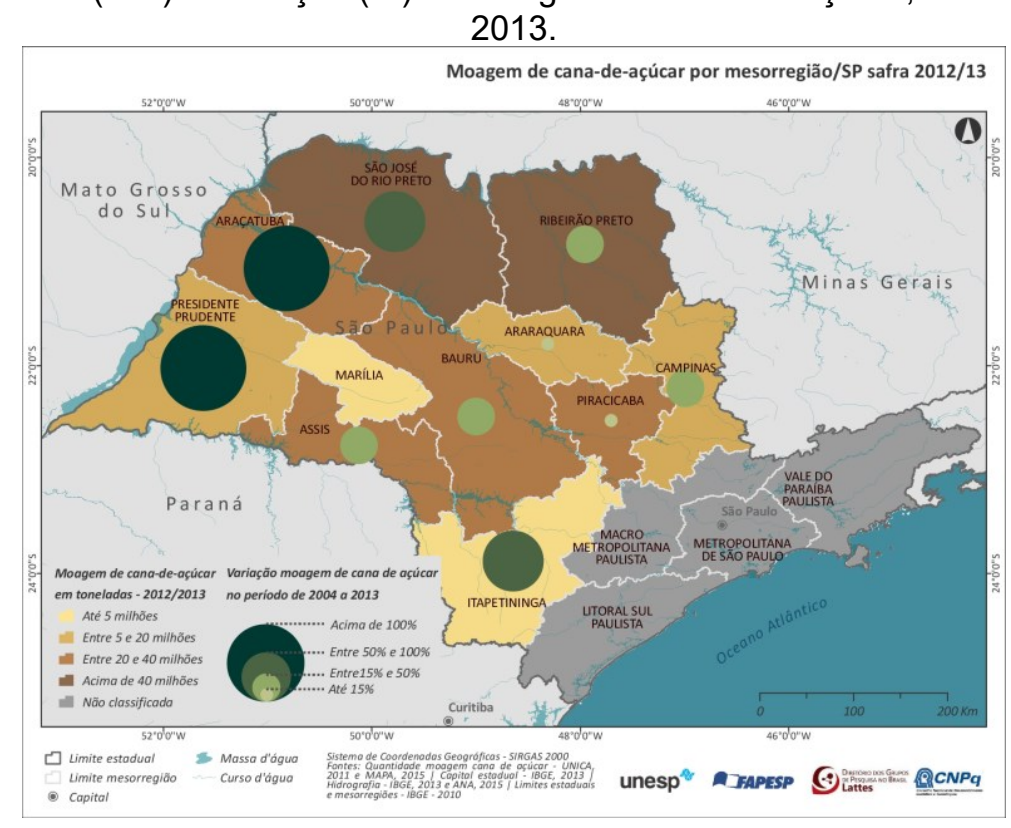


Este conjunto de dados das mesorregiões ratificam nossas considerações acerca das mudanças estruturais na base produtiva, no estabelecimento substituição de cultura, principalmente na expansão que se concretiza no eixo Centro/Oeste e Centro/Noroeste. Estas regiões apresentavam uma trajetória de ocupação em bovinocultura de corte e leite não especializada, citricultura em pequenas e médias propriedades e passam por um processo de reconversão produtiva extremamente acelerado. Esta velocidade que é demarcada pela expectativa de demanda, decorrente dos aportes financeiros na consolidação de estruturas de processamento, e que reverbera em um processo de demanda por terras e sua valorização, sobretudo para as propriedades que se encontram em raio médio de $75 \mathrm{~km}$ das unidades de processamento, considerando a perecibilidade da cana, no que se refere ao teor de sacarose.

Neste sentido, observa-se na Tabela 10 que as regiões consolidadas na produção de cana-de-açúcar apresentam variações de preços de terras para o período de análise, extremamente reduzidas e negativas (Guaíra, Pitangueiras, São Joaquim da Barra e Guariba), com exceção de Serrana, mas que tem seu comportamento extremamente influenciada por Ribeirão Preto e seu dinamismo econômico e de concentração de estruturas produtivas e gerenciais do setor. Ao passo que as áreas dos dois eixos assinalados, anteriormente, que parte da faixa central, como Barra Bonita, apresentam variação significativa de preços de terras. Esta lógica de determinação territorial, considerando os aspectos da estrutura social produtiva, como abordado, indica ainda, uma mudança conceitual na relação da terra como mercadoria, como terra de negócio e não terra de trabalho, ratificando a lógica fictícia que a terra representa, na composição de expectativa de produção e na composição do portfólio das empresas sucroenergéticas de capital aberto, o que alavanca seu valor intangível, no mercado de ações.

Tabela 10 - Preço médio da Terra Agrícola com cana-de-açúcar, em Reais de 2017 por hectare, para os anos de 2004, 2008 e 2012, para municípios selecionados.

\begin{tabular}{|c|c|c|c|c|}
\hline \multirow{3}{*}{ Municípios } & \multicolumn{3}{|c|}{$\begin{array}{l}\text { Preço médio da Terra agrícola } \\
\text { com cana-de-açúcar }(R \$ / h a)\end{array}$} & \multirow{2}{*}{$\begin{array}{l}\text { Variação } \\
(\%)\end{array}$} \\
\hline & 2004 & 2008 & 2012 & \\
\hline & (a) & (b) & (c) & (c/a) \\
\hline Barra Bonita & $14.086,69$ & $31.403,23$ & $27.281,40$ & 93,67 \\
\hline Catanduva & $22.500,89$ & $29.879,61$ & $29.634,71$ & 31,70 \\
\hline Guaíra & $30.941,24$ & $30.069,66$ & $33.992,25$ & 9,86 \\
\hline Guariba & $39.960,91$ & $32.836,65$ & $39.657,19$ & $-0,76$ \\
\hline Meridiano & $16.832,42$ & $16.849,96$ & $22.879,40$ & 35,92 \\
\hline Mirante do Paranapanema & $15.514,87$ & $10.542,90$ & $19.392,58$ & 24,99 \\
\hline Narandiba & $15.514,87$ & $10.542,90$ & $19.392,58$ & 24,99 \\
\hline Novo Horizonte & 0,89 & 9,61 & 29.6 & 31,70 \\
\hline Pereira Barreto & $16.824,37$ & $17.690,69$ & $22.117,19$ & 31,46 \\
\hline Pitangueiras & 1,24 & 30.0 & $33.992,25$ & 9,86 \\
\hline Promissão & $16.824,37$ & $17.690,69$ & $22.117,19$ & 31,46 \\
\hline Quatá & $15.514,87$ & $10.542,90$ & $19.392,58$ & 24,99 \\
\hline São Joaqu & $30.941,24$ & $30.069,66$ & $33.992,25$ & 9,86 \\
\hline Sebastianópolis do Sul & $18.755,44$ & $28.850,44$ & $28.217,49$ & 50,45 \\
\hline Serrana & $28.249,82$ & $32.883,35$ & $37.369,25$ & 32,28 \\
\hline
\end{tabular}

Nota: Valor obtido a partir de regiões geográficas, segundo metodologia específica do Anuário da Agricultura Brasileira - Agrianual.

Fonte: Agrianual (2006 e 2014).

Como salientado, a instalação das Usinas (Tabela 7) cria mudanças estruturais nas regiões agrícolas, antes mesmo de iniciarem suas operações. Observa-se que há mesorregiões que apresentaram desembolsos do BNDES (Tabelas 5 e 6) e não possuem unidades agroindustriais (Tabela 7) são: Macro Metropolitana Paulista, Metropolitana de São Paulo e Vale do Paraíba Paulista (com unidade da safra de 2008/09 até o ano de 2011). Das mesorregiões que apresentam as duas condições, destacam-se Campinas (10 unidades em 2013) e Itapetininga (4 unidades em 2013). Estas últimas apresentam variação da homogeneização da paisagem, visto que o índice de Theil para a primeira mesorregião era de 1,892 e passa para 1,902 e de Itapetininga era de 1,839 e foi para 1,913, na comparação do ano de 2004 e de 2012 (Tabela 11). Contudo, essa variação pode ser explicada pelo período de reforma de área de produção, com a inserção de atividades de produção de soja ou outras 
leguminosas (amendoim), via "rotação" de culturas, para fixação de nitrogênio no solo e replantio da cana-de-açúcar.

Tabela 11 - Índice de Theil para as mesorregiões do estado de São Paulo com recurso do BNDES para o setor sucroenergético, para os anos de 2000 a 2012.

\begin{tabular}{|c|c|c|c|c|c|c|c|}
\hline Mesorregião & 2000 & 2001 & 2002 & 2003 & 2004 & 2005 & \\
\hline Araçatuba & 1,528 & 1,475 & 1,444 & 1,492 & 1,543 & 1,497 & \\
\hline Araraquara & 1,179 & 1,207 & 1,146 & 1,134 & 1,121 & 1,126 & \\
\hline Assis & 1,492 & 1,496 & 1,578 & 1,589 & 1,556 & 1,550 & \\
\hline Bauru & 1,436 & 1,436 & 1,423 & 1,462 & 1,477 & 1,559 & \\
\hline Campinas & 1,889 & 1,898 & 1,871 & 1,883 & 1,892 & 1,883 & \\
\hline Itapetininga & 1,749 & 1,713 & 1,717 & 1,771 & 1,839 & 1,912 & \\
\hline Litoral Sul Paulista & 1,028 & 1,005 & 0,977 & 0,827 & 0,912 & 0,741 & \\
\hline Macro Metropolitana Paulista & 2,206 & 2,160 & 2,137 & 2,083 & 2,005 & 2,091 & \\
\hline Marília & 1,920 & 1,963 & 1,928 & 1,961 & 2,048 & 2,093 & \\
\hline Metropolitana de São Paulo & 2,210 & 2,062 & 1,878 & 1,896 & 1,870 & 1,828 & \\
\hline Piracicaba & 1,095 & 1,036 & 1,071 & 1,040 & 1,021 & 1,032 & \\
\hline Presidente Prudente & 1,974 & 2,036 & 1,939 & 1,903 & 1,855 & 1,857 & \\
\hline Ribeirão Preto & 1,604 & 1,542 & 1,518 & 1,486 & 1,459 & 1,443 & \\
\hline São José do Rio Preto & 1,888 & 1,853 & 1,830 & 1,843 & 1,866 & 1,797 & \\
\hline Vale do Paraíba Paulista & 1,715 & 1,754 & 1,630 & 1,606 & 1,610 & 1,597 & \\
\hline & 2006 & 2007 & 2008 & 2009 & 2010 & 2011 & 2012 \\
\hline Araçatuba & 1,250 & 1,082 & 0,927 & 0,694 & 0,778 & 0,703 & 0,693 \\
\hline Araraquara & 1,121 & 1,029 & 0,913 & 0,712 & 0,842 & 0,833 & 0,831 \\
\hline Assis & 1,508 & 1,482 & 1,459 & 1,440 & 1,470 & 1,423 & 1,532 \\
\hline Bauru & 1,442 & 1,363 & 1,286 & 1,162 & 1,175 & 1,188 & 1,312 \\
\hline Campinas & 1,804 & 1,737 & 1,701 & 1,694 & 1,671 & 1,659 & 1,902 \\
\hline Itapetininga & 1,877 & 1,912 & 1,892 & 1,953 & 1,949 & 1,963 & 1,913 \\
\hline Litoral Sul Paulista & 0,826 & 0,487 & 0,893 & 0,810 & 0,818 & 0,824 & 0,727 \\
\hline Macro Metropolitana Paulista & 2,086 & 2,105 & 2,007 & 1,964 & 2,015 & 1,989 & 2,106 \\
\hline Marília & 2,034 & 1,958 & 1,874 & 1,615 & 1,749 & 1,674 & 1,951 \\
\hline Metropolitana de São Paulo & 1,833 & 1,652 & 1,835 & 1,811 & 1,767 & 1,830 & 1,677 \\
\hline Piracicaba & 1,026 & 0,969 & 0,867 & 0,791 & 0,821 & 0,830 & 0,848 \\
\hline Presidente Prudente & 1,630 & 1,467 & 1,159 & 0,929 & 0,882 & 0,882 & 1,005 \\
\hline Ribeirão Preto & 1,360 & 1,179 & 1,156 & 0,995 & 0,986 & 0,966 & 1,085 \\
\hline São José do Rio Preto & 1,574 & 1,392 & 1,239 & 1,042 & 0,986 & 1,022 & 0,970 \\
\hline Vale do Paraíba Paulista & 1,592 & 1,555 & 1,584 & 1,694 & 1,631 & 1,618 & 1,382 \\
\hline
\end{tabular}

Fonte: IBGE (2017).

De todas as formas, esta mudança ou reconversão produtiva se materializa como uma determinação singular que, segundo Silva (2005), se espelha como um "mar de cana". Souza (2013) apresenta a tendência de homogeneização territorial no estado de São Paulo, principalmente nas áreas de ocupação de cana-de-açúcar, sejam as tradicionais (Ribeirão Preto e Piracicaba) como as de expansão (Adamantina e Presidente Prudente). Para o autor, a homogeneização da paisagem e territorial anula a diversidade produtiva, como se fosse um movimento geofágico, que incorpora as terras em sua exagerada apetência e absorve a diversidade por meio da imposição de um modelo técnico-científico.

Este movimento de homogeneização territorial como uma determinação de poder sobre as relações produtivas impostas pelo setor sucroenergético e mediadas pelo BNDES, se estabelece de forma expressiva nas mesorregiões de Araçatuba, Presidente Prudente e São José do Rio Preto as mais homogêneas, onde se encontram 7 dos 15 municípios (Pereira Barreto, Mirante do Paranapanema, Narandiba, Catanduva, Meridiano, N. Horizonte e Sebastianópolis do Sul) com captação superior a $\mathrm{R} \$ 350$ milhões, que totalizam $\mathrm{R}$ \$ 3,6 bilhões, e que apresentaram variação positiva no preço médio da terra agrícola (Tabela 10). Além disso, regiões "tradicionais" de uso e ocupação do setor sucroenergético, como Ribeirão Preto, Araraquara e Piracicaba, também, acusam baixo índice de diversidade produtiva (Theil) no ano de 2012. As duas últimas mesorregiões não estão entre as que mais receberam desembolso do BNDES, mas são regiões que apresentaram aumento da área colhida, da quantidade produzida e da moagem de cana-de-açúcar (Tabelas 8 e 9), mesmo com a diminuição do número de unidades agroindustriais (Tabela 7), o que consolida um processo de monopolização do território (OLIVEIRA, 2012). 
Nas Figuras 8,9 e 10 apresenta-se a trajetória de homogeneização nas mesorregiões paulistas (2000, 2006 e 2013), uma efetiva redução do número de culturas por área no estado de São Paulo, com padrões inferiores a 1,500 .

Figura 8 - Padrão de homogeneização da paisagem, mesorregião/SP, 2000

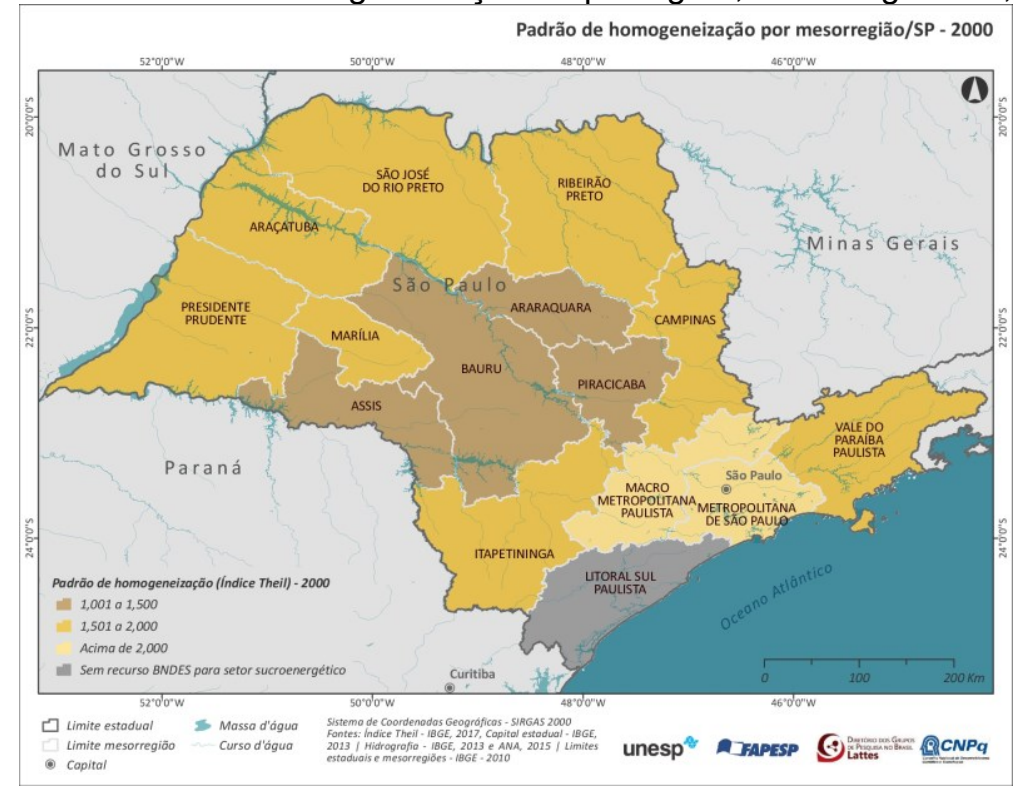

Figura 9 - Padrão de homogeneização da paisagem, mesorregião/SP, 2006.

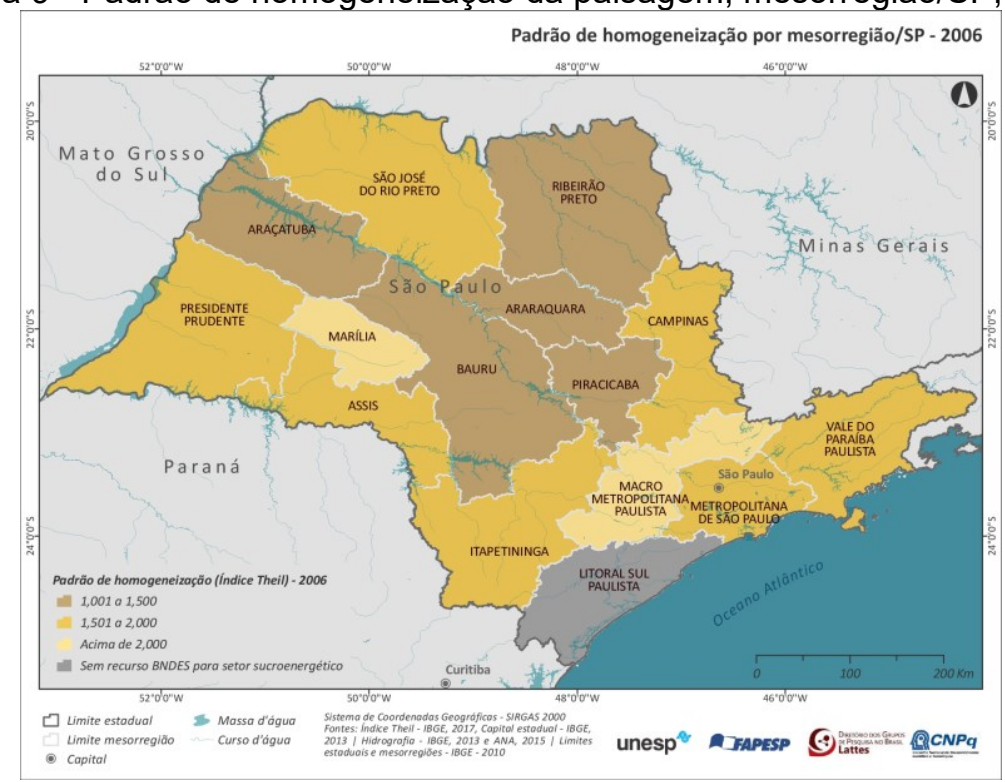

Para apresentar um parâmetro do acentuado grau de homogeneização no estado de São Paulo, Souza e Cabero Diegues (2012) analisaram a Espanha (país de clima mediterrâneo e com capacidade de resposta ecológica extremamente diferenciada em relação aos trópicos), no ano de 2008, e verificaram que, apesar do incremento às políticas de produção de biocombustíveis na União Europeia, os índices eram superiores a 3,0. Isto denota uma diversidade produtiva extremamente mais significativa que as áreas de domínio do setor sucroenergético no Brasil.

Ainda mantendo uma relação de análise entre recursos e padrão de homogeneização da paisagem, verifica-se que a mesorregião de Ribeirão Preto detém 4 dos 15 municípios com captação acima de 
$R \$ 350$ milhões, somando $R \$ 2,4$ bilhões, dos quais $R \$ 938,6$ milhões foram destinados ao município de Guaíra.

Figura 10 - Padrão de homogeneização da paisagem, mesorregião/SP, 2012.

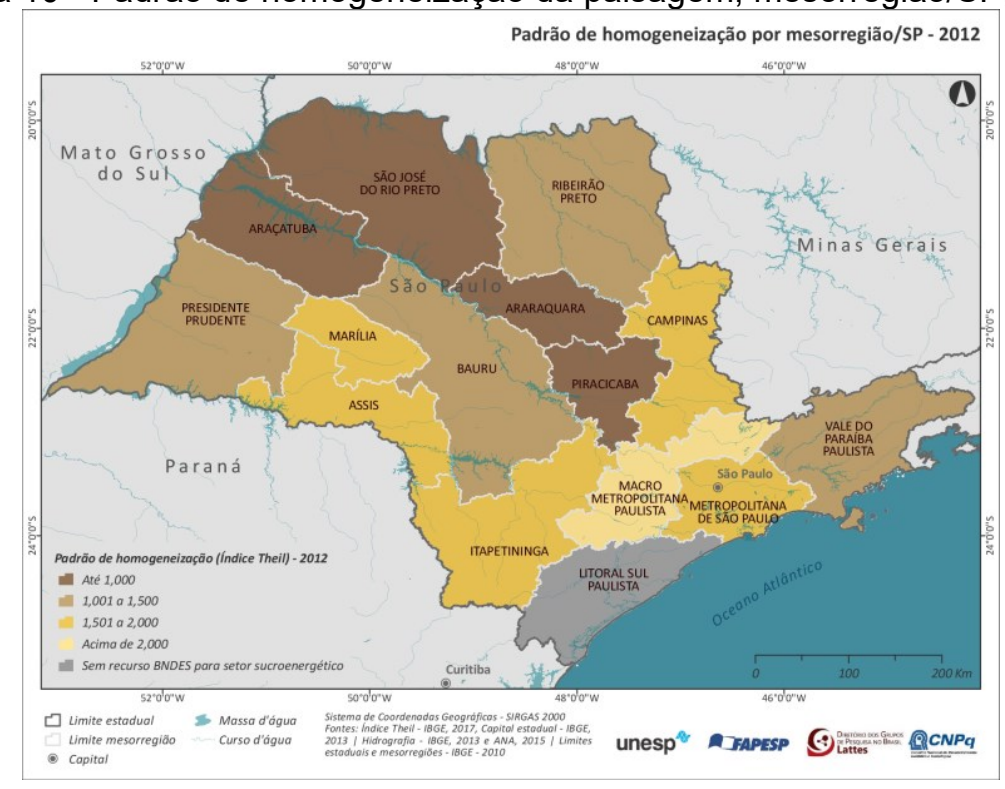

Os municípios com este patamar de recursos (acima de $\mathrm{R} \$ 350$ milhões) reúnem representatividade dos desembolsos médios do BNDES em relação a receita municipal média, exceto para Catanduva (Tabela 12). Nos municípios de Sebastianópolis do Sul, Meridiano, Narandiba, Quatá, Mirante do Paranapanema e Pereira Barreto, o volume de recursos do BNDES frente às receitas médias municipais, que coincidentemente são municípios das mesorregiões de expansão espacial do setor (Araçatuba, Assis, Presidente Prudente e São José do Rio Preto), superam em 2 ou 3 vezes a receita média anual no período de 2004-2011.

Tabela 12 - Receita Municipal média (2004 a 2011) e Desembolso médio do BNDES (2004 a 2012), em Reais de 2017, para municípios selecionados.

\begin{tabular}{lr|r|r}
\hline \multicolumn{1}{c}{ Municípios } & $\begin{array}{c}\text { Receita Municipal } \\
\text { Média R\$ } \\
(\mathrm{a})\end{array}$ & $\begin{array}{c}\text { Desembolso Médio } \\
\text { do BNDES R\$ } \\
\text { (b) }\end{array}$ & $\begin{array}{r}\text { Participação \% } \\
\text { (b/a) }\end{array}$ \\
\hline Barra Bonita & $82.483 .555,00$ & $55.381 .881,81$ & 67,14 \\
Catanduva & $315.713 .554,50$ & $58.980 .700,22$ & 18,68 \\
Guaíra & $122.731 .517,13$ & $104.293 .202,60$ & 84,98 \\
Guariba & $76.891 .049,25$ & $44.429 .401,15$ & 57,78 \\
Meridiano & $13.778 .801,38$ & $47.708 .384,50$ & 346,24 \\
Mirante do Paranapanema & $30.768 .753,25$ & $64.772 .723,63$ & 210,51 \\
Narandiba & $17.896 .402,50$ & $59.049 .492,34$ & 329,95 \\
Novo Horizonte & $81.954 .521,88$ & $57.710 .145,60$ & 70,42 \\
Pereira Barreto & $58.342 .546,63$ & $65.022 .149,38$ & 111,45 \\
Pitangueiras & $67.454 .622,13$ & $58.862 .126,19$ & 87,26 \\
Promissão & $60.047 .848,00$ & $40.815 .319,54$ & 67,97 \\
Quatá & $34.061 .081,25$ & $74.485 .046,92$ & 218,68 \\
São Joaquim da Barra & $69.346 .075,13$ & $67.050 .858,99$ & 96,69 \\
Sebastianópolis do Sul & $13.939 .982,13$ & $52.148 .332,10$ & 374,09 \\
Serrana & $90.793 .788,63$ & $59.042 .733,58$ & 65,03 \\
\hline
\end{tabular}

Fonte: BNDES (2010 e 2013a) e SEADE (2017)

Por fim, pode-se ressaltar que o volume de recursos liberados pelo BNDES para o setor sucroenergético no estado de São Paulo atende tanto áreas tradicionais (Piracicaba, Ribeirão Preto, Araraquara) como de expansão do setor sucroenergético (Araçatuba, Assis, Presidente Prudente, São José do Rio Preto), inclusive contribui para a consolidação deste setor nas novas áreas. Com 
isso, verifica-se que os fundos públicos dinamizam a atuação do setor em uma proporção completamente díspar da realidade econômica dos municípios em que se insere. É importante demarcar, também, que este volume de recursos do BNDES disponibilizados ao setor está atrelado a relevância que este assume na economia nacional vis-à-vis a balança comercial, a demanda doméstica de energia por combustível alternativo (tecnologia flex fuel), bem como aos acordos ambientais firmados pelo Estado brasileiro, sobretudo no que diz respeito a emissão de CO2.

\section{CONSIDERAÇÕES FINAIS}

Este processo de captação de recursos demonstra a imbricada relação entre mercado e Estado, e como este último opera a partir de suas estruturas (BNDES), no processo de dinamização e ampliação na realização do valor e de seu padrão de acumulação, visto o volume de desembolsos nos períodos analisados, que somam mais de $\mathrm{R} \$ 63$ bilhões. Da mesma forma, tem-se a importância e a centralidade do estado de São Paulo para o setor sucroenergético, visto o montante de $\mathrm{R} \$ 35$ bilhões de créditos recebidos de 2001 a 2012.

Os anos com maior volume de captação pelo setor sucroenergético paulista foram os anos de 2007 , 2008 e 2010 que coincidem com o período de maior crescimento da área colhida de quantidade produzida de cana-de-açúcar, bem como o maior nível de quantidade produzida de cana-de-açúcar por hectare. Outra constatação é de que houve crescimento na moagem de cana-de-açúcar e produção de açúcar e etanol total, no período da safra de 2004/05 ao de 2012/13. Este crescimento está relacionado, principalmente, aos tipos de desembolsos mais relevantes em volume de recursos que são, no período de 2001 a 2008, para 'expansão', 'financiamento de compra de máquinas e serviços' e 'implantação' e, de 2009 a 2012, para 'fabricação de açúcar em bruto' e 'cultivo de canade-açúcar'.

Os municípios paulistas em que o setor sucroenergético recebeu maior volume de recursos do BNDES, de 2004 a 2012, são Guaíra (R\$ 939 milhões), Quatá (R\$ 670 milhões), São Joaquim da Barra (R\$ 603 milhões), Pereira Barreto (R\$ 585 milhões), Mirante Paranapanema (R\$ 583 milhões), Catanduva (R\$ 531 milhões), Narandiba (R\$ 531 milhões), Serrana (R \$ 531 milhões), Pereira Barreto (R\$ 530 milhões) e Novo Horizonte (R\$ 519 milhões), que juntos somam aproximadamente R\$ 6,02 bilhões. Nesse mesmo período, das mesorregiões com maior captação de recursos pelo setor sucroenergético têm-se Ribeirão Preto (R\$ 7,4 bilhões), São José do Rio Preto (R\$ 5,8 bilhões), Bauru (R\$ 3,9 bilhões), Araçatuba (R\$ 3,2 bilhões), Assis (R $\$ 2,5$ bilhões) e Presidente Prudente (R\$ 2,2 bilhões) que somam $\mathrm{R} \$ 24,95$ bilhões e apresentam o maior número de unidades agroindústrias sucroenergéticas. Estas mesorregiões são as que têm maior área colhida e quantidade produzida de cana-de-açúcar. Os maiores crescimentos nestes quesitos e em moagem de cana-de-açúcar são identificados nas mesorregiões de São José do Rio Preto, Araçatuba e Presidente Prudente.

Dessas seis mesorregiões, as que apresentam maior homogeneização são Araçatuba $(0,69)$ e São José do Rio Preto $(0,97)$. É importante assinalar que essa tendência de homogeneização também se estabelece em mesorregiões tradicionais no setor sucroenergético, como Araraquara e Piracicaba. Estes desembolsos contribuem para a manutenção da predominância do estado de São Paulo no setor sucroenergético, com a manutenção das mesorregiões tradicionais e com a expansão do setor para novas regiões do estado. Recursos que contribuem para a homogeneização territorial das mesorregiões e, com isso, para a consolidação de setor hegemônico e produtor de commodities que reforça uma pauta de exportação primária, determinante da condição dependente da economia brasileira na divisão internacional do trabalho. Tem-se que o destino destes recursos depende da demanda privada e do interesse do Estado que é viabilizado via BNDES, em detrimento de uma lógica de Estado que priorize o desenvolvimento econômico sem prejuízo as questões sociais, ambientais e locais, temas que devem ser analisados, visto a sua importância e, com isso, estabelecer a relação dos recursos provenientes do BNDES ao setor sucroenergético com as questões sociais e ambientais. Demarca-se que o conjunto de determinações territoriais que se inicia pelo padrão de homogeneização da paisagem se reverberam, na formação bruta do capital fixo, na ocupação de terras, na dinâmica de seus preços, na competição com outras atividades produtivas que apresentam dinâmicas menos excludentes, menos monopolizadoras. Atividades de produção, sobretudo quando alimentares, que reduzem ou não aceleram o caráter rentista da agricultura paulista, que se revela em uma determinação territorial quase que absoluta no setor sucroenergético, mediada pela mudança da relação com a terra (arrendamento) ou a titularidade da propriedade (venda). 


\section{AGRADECIMENTOS}

Agradecimento à Fundação de Amparo à Pesquisa do Estado de São Paulo.

\section{REFERÊNCIAS}

AGRIANUAL. Anuário da agricultura brasileira. 11. ed. São Paulo: FNP, 2006.

. Anuário da agricultura brasileira. 19. ed. São Paulo: FNP, 2014.

BACCARIN, J.G. Efeitos ambientais, sociais e econômicos de mudanças tecnológicas recentes na cana-de-açúcar no estado de São Paulo, Brasil. Revista Pegada, Presidente Prudente, v.20, n.3, p. 142 - 173, set./dez. 2019. https://doi.org/10.33026/peg.v3i20.6559

BELIK, W.; VIAN, C.E.F. Desregulamentação estatal e novas estratégias competitivas da agroindústria canavieira em São Paulo. In: MORAES, M.F.F.; SHIKIDA, P.F. (org.) Agroindústria canavieira no Brasil: evolução, desenvolvimento e desafios. São Paulo: Atlas, 2002. p. 69-92.

BNDES - Banco Nacional de Desenvolvimento Econômico e Social. Desembolso do sistema BNDES para - setor sucroalcooleiro segundo o objetivo. (2001-2008). Informações recebidas mediante solicitação, 2010.

Desembolso do sistema BNDES para o setor sucroalcooleiro segundo o objetivo. (2009-2012). Informações recebidas mediante solicitação, 2013a.

Relatório anual BNDES 2012. Rio de Janeiro: BNDES, 2013b. 100 p. Disponível em: https://web.bndes.gov.br/bib/jspui/handle/1408/931. Acesso em: 30 mai. 2020.

Relações com Investidores. Fontes de Recursos. 2020. Disponível em: https://www.bndes.gov.br/wps/portal/site/home/relacoes-com-investidores/fontes-de-recursos. Acesso em: 30 mai. 2020.

BORGES, A.C.G.; BRUMATTI, L. M. Desembolsos do BNDES no setor sucroalcooleiro no nordeste brasileiro. Revista de Geografia, Recife, v. 36, n. 1, p. 110-131. 2019

BRASIL. [Constituição (1988)]. Constituição da República Federativa do Brasil. Promulgada em 5 de outubro de 1988. Disponível em http://www.planalto.gov.br/ccivil_03/constituicao/constituição.htm. Acesso em: 15 mar. 2018.

Biblioteca do Presidente. Discurso do Presidente da República, Luiz Inácio Lula da Silva (Abertura do Debate-Geral da $62^{\mathrm{a}}$ Assembleia-Geral das Nações Unidas). 2007. Disponível em: http://www.biblioteca.presidencia.gov.br/presidencia/ex-presidentes/luiz-inacio-lula-da-silva/discursos/2omandato/2007/25-09-2007-discurso-do-presidente-da-republica-luiz-inacio-lula-da-silva-na-abertura-do-debate-geralda-62a-assembleia-geral-das-nacoes-unidas/view . Acesso em: 28 mai. 2020.

BUGIATO, C. A política de financiamento do BNDES e a burguesia brasileira. Cadernos do Desenvolvimento, Rio de Janeiro, v. 9, n. 14, p.83-103, jan.-jun. 2014

DELGADO, G. C. Especialização primária como limite ao desenvolvimento. Desenvolvimento em Debate, Rio de Janeiro, v.1, n.2, p.111-125, janeiro-abril e maio-agosto 2010.

FGV - Fundação Getúlio Vargas. Instituto Brasileiro de Economia - IBRE. Índice Geral de Preço, 2017. Disponível em: http://portalibre.fgv.br/main.jsp?lumChannelld=402880811 D8E34B9011D92B6B6420E96. Acesso em: 20 mar. 2018.

HARVEY, D. A produção capitalista do espaço. São Paulo, Annablume, 2005.

. Limits to capital. New York, Verso, 2006.

IBGE - Instituto Brasileiro de Geografia e Estatística. Banco de Dados Agregados - SIDRA. Disponível em: http://www.sidra.ibge.gov.br/. Acesso em: 25 nov. 2017.

KLOSS, E. C. Transformação do etanol em commodity perspectivas para uma ação diplomática brasileira. Brasília, Funag/Ministério das Relações Exteriores, 2012. 232 p. Disponível em: http://funag.gov.br/biblioteca/download/0950-Transformacao-do-Etanol-em-Commodity-corrigido.pdf. Acesso em: 28 mai. 2020. 
KON, A. Concentração e Centralização do Capital. In: KON, A. Economia industrial. São Paulo, Nobel, p. 47-66, 1994.

MAPA. SPA. Departamento da cana-de-açúcar e agroenergia. Relação das unidades produtoras cadastradas por município. 2011, 2012 e 2013. (Vários números). Disponível em: http://www.agricultura.gov.br/. Acesso em: 20 de novembro de 2019.

MILANEZ, A.Y.; BARROS, N.R.; FAVERET FILHO, P.S.C. O perfil do BNDES ao Setor sucroenergético. Setor Sucroenergético. Rio de Janeiro, BNDES, 2008. 34 p.

RAFFESTIN, C. Por uma Geografia do Poder. São Paulo: Ática. 1993

SILVA, M. A. Trabalho e trabalhadores na região do "Mar de Cana e do Rio de Álcool". Agrária (Online), São Paulo, n. 2, p. 2-39, 2005. https://doi.org/10.11606/issn.1808-1150.v0i2p2-39

OLIVEIRA, A. U. A Mundialização da Agricultura Brasileira. In: Colóquio Internacional de Geocrítica, XII, 2012, Bogotá. Actas [...]. Barcelona: Geocrítica, 2012. v.1.p. 1-15.

A mundialização da Agricultura Brasileira. São Paulo, landé Editorial, 2016. 545 p.

SEADE. Fundação Sistema Estadual de Análise de Dados. Informações dos Municípios Paulistas (IMP). Disponível em: http://www.seade.gov.br/produtos/imp/. Acesso em: 23 de jan. 2017.

SOUZA, J.G. Questão de Método: a homogeneização territorial paulista. 2008, 167 p. (Tese de Livre Docência) - Faculdade de Ciências Agrárias e Veterinárias, UNESP, Jaboticabal -SP.

. A produção brasileira de etanol e seus efeitos sobre o valor da terra, sobre a concentração fundiária e sobre a homogeneização da paisagem. Diversitates, Rio de Janeiro, v. 5, p. 29-58, 2013.

; BORGES, A.C.G. As determinações territoriais da lógica do valor e do autovalor - análise da produção de soja no Mato Grosso - Brasil. In: JACINTO, R. Iberografias: Outras Fronteiras, Novas Geografias: Intercâmbios e Diálogos Territoriais. Guarda-Portugal: Europress - Indústria Gráfica/Centro de Estudos Ibérico, v. 32, p. 247-270, 2017.

; CABERO DIEGUES, V. Por uma desglobalização da produção alimentar - commoditização da agricultura e diversidade produtiva: uma análise de Espanha. Revista Geographia, Rio de Janeiro, v. 14, n 28, p. 63-81, 2012. https://doi.org/10.22409/GEOgraphia2012.1428.a13643

SOUZA, Z. J. Evolução e considerações sobre a co-geração de energia no setor sucroenergético. In: MORAES, M.A.F.D.; SHIKIDA, P.F. (org.) Agroindústria canavieira no Brasil: evolução, desenvolvimento e desafios. São Paulo: Atlas, p. 214-240, 2002.

UNICA. União da Indústria de Cana-de-açúcar. Ranking de produção das unidades da região Centro-Sul, safras 2004/2005, 2005/2006, 2006/2007 e 2007/2008. 2011. Disponível em: http://www.unica.com.br/dadosCotacao/estatistica/. Acesso em: 22 jan. 2011.

Recebido em: 11/12/2019

Aceito para publicação em: 15/07/2020 